\title{
Essays in Macroeconomics
}

\author{
İlhan Güner \\ Istanbul, Turkey
}

M.A. Economics, University of Virginia, 2012

M.A. Economics, Koc University, 2010

B.A. Business Administration, Bogazici University, 2008

A Dissertation presented to the Graduate Faculty

of the University of Virginia in Candidacy for the Degree of Doctor of Philosphy

Department of Economics

University of Virginia

May, 2017 


\begin{abstract}
This dissertation consists of two chapters. The first chapter, titled 'Growth and Welfare Implications of Sector-Specific Innovations,' identifies the optimal government support of business research and development $(\mathrm{R} \& \mathrm{D})$ activities when sectors are heterogeneous. To this end, I build an endogenous growth model in which firm R\&D drives macroeconomic growth and firm dynamics in two sectors that have different characteristics: a consumption-goods sector and an investment-goods sector. I calibrate my model to U.S. data. To quantitatively characterize the optimal R\&D subsidy rate for each sector, I simulate the economy with various R\&D subsidy rates that range from 0 to 90 percent. By explicitly examining the transition path after a change in subsidy rates, I highlight the tradeoff between the consumption level in short-run and long-run growth. I find that the optimal combination of the subsidy rates is 82 percent in the consumption sector and 78 percent in the investment sector. By moving from the baseline subsidy rates (20 percent in each sector), society can achieve a 15 percent welfare gain in consumption-equivalent terms. The investment sector R\&D subsidy generates three quarters of this welfare gain. The socially optimal subsidy system increases the annual GDP growth rate from 2 percent to 3.3 percent. I also find that when the government transfer budget is limited, the consumption sector R\&D should be subsidized at a higher rate than the investment sector.

The second chapter, 'Worker Flows over the Life Cycle,' is coauthored with Tomaz Cajner at the Federal Reserve Board and Toshihiko Mukoyama at the University of Virginia. Using Current Population Survey data, we document monthly movements across three labor market states (employment, unemployment, and out of labor market) and transitions across jobs during the life cycle of individuals. The data shows
\end{abstract}


that worker flows vary substantially over the life cycle. Most labor market transition rates go down as people age, while transitions out of the labor market increase later in the life cycle of workers. We build a partial-equilibrium model of the worker life cycle that features saving decisions, idiosyncratic worker productivity shocks, and match quality shocks. We use the model to identify the forces that lead to observed patterns of worker flows over the life cycle and over the business cycle.

JEL Classifications: E21, E22, O31, O38, L16, D91, E24, J64

KEywords: Endogenous Growth, Innovation, R\&D, Firm Dynamics, SectorSpecific Technological Change, Worker Flows, Life Cycle 


\section{Acknowledgements}

I would like to express deep gratitude to my thesis committee members, Toshihiko Mukoyama, Eric Young, Sophie Osotimehin, and Kieran J. Walsh, my friends, and my family.

I am extremely grateful to my advisor, Toshihiko Mukoyama. Without his guidance and support, I will not be able to complete this dissertation. He always encouraged me to do high quality research, guided me in refining my ideas, directed me to the right resources, and advised me to do proper analysis to answer my research questions. When I stumbled, he helped me to remove the road blocks. When I focused on short-term costs instead of long-term benefits, he patiently reminded me of the future. I would like to thank him so much for being a wonderful person and advisor.

I thank Eric Young for being a demanding and but also supportive advisor. He asked critical questions, pointed out the problems in my research, demanded a proper explanation of the concepts in my research. But also, he helped me to answer such critical questions, to fix the problems in my research, and to better communicate my research.

Sophie Osotimehin and Latchezar Popov have attended presentation of my research many times, read drafts of my research and given highly valuable feedback. Latchezar continued to provide support even after he left Charlottesville, VA. I am so thankful to both of them. I also would like to thank Zach Bethune, Ana Fostel, Jae Won Lee, Eric van Wincoop, and Marc Santugini for allocating their time to listen to my research and giving constructive feedback.

I would like to thank my friends Allison Oldham Luedtke, Abiy Teshome, Nick Embrey, Jeff Schafer, Nate Pattison, and Selcen Cakir for their help in my dissertation. 
A very special thanks to my friend Selcen Cakir for being there when I needed help and providing emotional support when I needed the most.

I thank very deeply to my parents Hayriye and Ahmet, and my brother Erhan. Though I was thousands of miles away from them, I always felt their support. Without their continuous love and support, it would be orders of magnitude harder to complete this dissertation.

I also thank UVA Bankard Fund for Political Economy for the financial support in this thesis. 


\section{Contents}

1 Growth and Welfare Implications of Sector-Specific Innovations 1

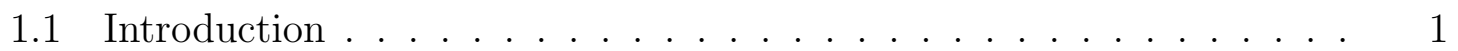

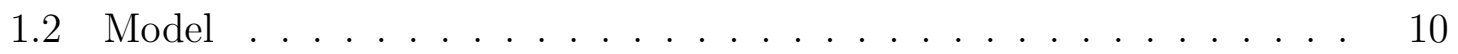

1.2 .1 Households . . . . . . . . . . . . . . . . . . . . . . 10

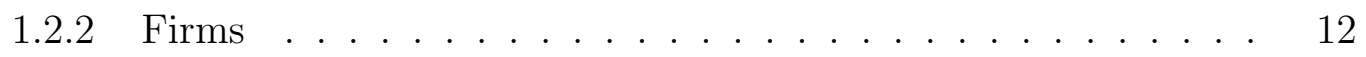

1.2 .3 Innovation by Incumbents . . . . . . . . . . . . . . . . . . . 12

1.2 .4 Consumption Goods Producers . . . . . . . . . . . . . . 13

1.2 .5 Investment Goods Producers . . . . . . . . . . . . . . 16

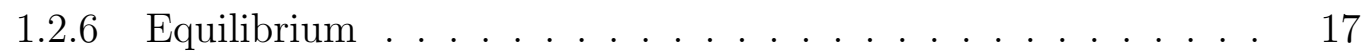

1.3 Calibration $\ldots \ldots \ldots \ldots \ldots n$

1.4 Growth Decomposition . . . . . . . . . . . . . . . . . . . . 23

1.5 Optimality of Innovation $\ldots \ldots \ldots \ldots$

1.5 .1 Social Optimum . . . . . . . . . . . . . . . . . . . 25

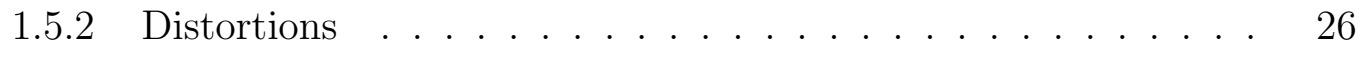

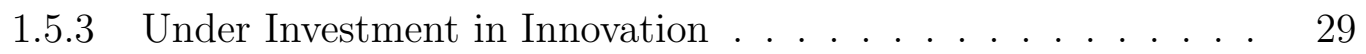

1.6 Innovation Subsidies $\ldots \ldots \ldots \ldots \ldots$

1.6 .1 Welfare Gain with Limited Transfer Budget . . . . . . . . . 40

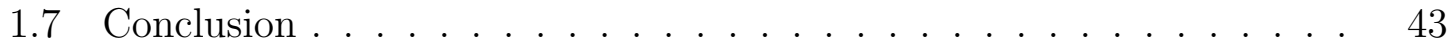

\begin{tabular}{|ll}
\hline Appendix A Appendix to Chapter 1 & 47
\end{tabular}

A.1 Industry Classification . . . . . . . . . . . . . . . . . . 47

A.2 Solution of the Model . . . . . . . . . . . . . . . . . . . . 48

A.2.1 Balanced Growth Path . . . . . . . . . . . . . . . . . 51

A.2.2 Growth Rates of Average Quality Levels . . . . . . . . . . 52

A.3 R\&D Expenditure as a Share of GDP . . . . . . . . . . . . . 53

2 Worker Flows over the Life Cycle 54

2.1 Introduction $\ldots \ldots \ldots \ldots \ldots \ldots \ldots \ldots \ldots \ldots$

2.2 Related Literature $\ldots \ldots \ldots \ldots \ldots$

2.3 Empirical Observations $\ldots \ldots \ldots \ldots \ldots$

2.3 .1 Data $\ldots \ldots \ldots \ldots \ldots \ldots$ 
2.3 .2 Labor Market Stocks . . . . . . . . . . . . . . . . . . . . . . . 59

2.3 .3 Labor Market Flows . . . . . . . . . . . . . . . . . . . . . . . 60

2.3 .4 Business Cycles - The Great Recession . . . . . . . . . . . . . 63

2.3 .5 Job-to-Job Transitions . . . . . . . . . . . . . . . 63

2.4 Model $\ldots \ldots \ldots \ldots$

2.4 .1 Technology and Preferences . . . . . . . . . . . . . . . . 66

2.4 .2 Initial Match Quality Draws . . . . . . . . . . . . . . . . . 67

2.4 .3 Timing . . . . . . . . . . . . . . . . . . . 67

2.4 .4 Bellman Equations for Workers . . . . . . . . . . . . . . 68

2.5 Calibration . . . . . . . . . . . . . . . . . . . . . 70

2.6 Results . . . . . . . . . . . . . . . . . . . . . . . . . . . . . . 72

2.6 .1 Business Cycle Implications of the Model . . . . . . . . . . . . 75

2.7 Conclusion . . . . . . . . . . . . . . . . . . . . . 78 


\section{Chapter 1}

\section{Growth and Welfare Implications of Sector-Specific Innovations}

\section{$1.1 \quad$ Introduction}

Governments support business research and development (R\&D) in varying amounts. In 2011, the United States federal government's total support to business R\&D was $0.26 \%$ of its GDP. The fraction was $0.43 \%$ in Korea and $.01 \%$ in Mexico OECD (2015)]. Inter-country variation in the government support of R\&D suggests that setting the optimal amount of support is not straightforward. In this paper, I characterize the optimal amount of government subsidy to business $R \& D$ in a quantitative environment.

I build an endogenous growth model with firm dynamics to analyze the optimal R\&D subsidy. I use the model and firm dynamics data to identify inefficiencies in the R\&D expenditures of two sectors that have different characteristics: the consumptiongoods sector and the investment-goods sector. Next, I characterize the subsidy rates 
in these sectors that are needed to correct inefficiencies in innovation. I base my model on the seminal work of Klette and Kortum (2004), in which innovation by incumbent and entering firms generates firm dynamics and derives macroeconomic growth. Klette and Kortum show that their model can qualitatively account for various stylized facts about firm dynamics. Hence, I identify the inefficiencies in the firm R\&D expenditures with a framework that has a good fit on the firm dynamics data. I extend the Klette and Kortum model by introducing capital stock and by having not only consumption-goods sector but also investment-goods sector. Firm entry and expansion rate differences across these sectors and the sustained decline in the prices of investment goods relative to consumption goods, observed in the data (developed by Gordon (1990), and extended by Cummins and Violante (2002)), imply that in these sectors there are different magnitudes of inefficiency and rates of technological change. A model that takes the heterogeneity of innovative activity across sectors into account will provide more accurate information about the growth and welfare implications of R\&D subsidies.

In this paper, an innovation is modeled as an increase in the quality of an existing good in the market along a quality ladder. My two sectors consist of many differentiated products, each of which is produced by a production line. In this setting, firms are simply collections of the production lines they possess. Innovating firms capture the market of the innovated product from the existing producer and earn monopoly rents, which last as long as the innovators hold the blueprints of the highest quality versions of the goods they produce. Firms lose these rents following innovation on the same goods by other firms. Firms, therefore, expand and shrink according to this creative-destruction process, entering the market when they successfully innovate and exiting if they lose the blueprints of all the goods they produce. 
In a market economy the creative-destruction process contains inefficiencies, which lead to differences in market economy and social planner innovation rates in each sector. Innovation rate in a sector is defined as the measure of differentiated products innovated at a time over the measure of total products in that sector. An innovator reaps monopoly rents as long as it holds the blueprints of the highest-quality version of the product she innovated. However, the benefit of innovation to the society is the extra production from the innovation, which may be different from the monopoly rents. Also, unlike a limited lifetime of monopoly rents that accrue to the innovator, the social benefit of the innovation lasts forever. On the one hand, an entrepreneur's inability to appropriate all of the consumer surplus it created causes market economy innovation rates to fall below those of social planner levels (the appropriability effect). Also, the limited time of monopoly rents that accrue to the innovator contributes to under investment in innovation (the inter-temporal spillover effect). On the other hand, an entrepreneur does not take into account the profit loss that is imposed on the current producer of the product that they have taken over, and this moves market innovation rates above the socially efficient level (the business-stealing effect). Depending on the sizes of these distortions, market economy innovation rates can be below or above the socially efficient levels. Therefore, a government may be able to employ tax/subsidy systems to correct the distortions in the economy, which increases the welfare of households.

Setting the optimal amount subsidy for each sector requires knowledge of the elasticity of R\&D with respect to the subsidy and the magnitudes of externalities in each sector. Various studies have estimated the former using data on firm level R\&D expenditures and changes in government subsidy rates Bloom et al. (2002), Hall et al. (2010), CBO (2005)]. The magnitudes of externalities are not observable. 
To infer the sizes of externalities in each sector and devise the optimal R\&D subsidy system, I identify model parameters related to innovation that are obtained from the model's implications on firm dynamics. Recent literature emphasizes that the firm dynamics data contains important information about the innovation process. Klette and Kortum (2004) show that their model qualitatively generates many empirical facts on firm size distribution and firm growth rates. Lentz and Mortensen (2008), whose model is based on Klette and Kortum, estimate model parameters from Danish data, and the model quantitatively fits related firm dynamics moments.

Differences in the firm dynamics of the two sectors, as observed in the US data, imply that in the two sectors there are different magnitudes of externalities. In the model, the expected lifetime of monopoly rents that accrue to an innovator after successful innovation is linked to the entry rate in the firm's sector (the inter-temporal spillover). Hence, a higher entry rate in the consumption sector suggests a larger inter-temporal spillover effect. The business-stealing effect is about the difference between the profit an innovating firm captures and the net benefit of innovation to the society, including the profit loss the incumbent producer faces after an innovation. The net benefit of innovation to society is the extra production it enables, which is summarized by the size of the quality improvement (the quality ladder step size). The lower the quality ladder step size, the lower the benefit of innovation to society, and the larger the difference between the private and social benefits of an innovation. Therefore, the business-stealing effect is inversely related to the quality ladder step size. The GDP growth rate and the growth rate of the investment goods price relative to the consumption goods price identifies the quality ladder step size in each sector. The calibration exercise shows that the consumption-goods sector has lower quality ladder step size than the investment-goods sector. Because of the inverse relationship 
between the quality ladder step size and the business stealing effect, the consumptiongoods sector experiences a larger business-stealing effect.

After calibrating my model to the US firm dynamics data, I decompose longrun GDP growth into the contributions of each sector. It turns out that 66 percent of growth is due to innovation activities in the investment-goods sector. A larger quality ladder step size in the investment-goods sector is the main reason for the dominant share of its contribution to growth. This high level of contribution recalls the empirical findings of Sakellaris and Wilson (2004), who report that two thirds of technological progress is attributable to investment-specific technological change. Krusell (1998) develops an endogenous growth model that can account for the decline in the relative price of investment goods. Like me, he attributes approximately half of the consumption growth to investment specific technological change. Moreover, in my analysis, entrants contribute to one-third of consumption growth. My findings regarding the contribution of entrants to growth are comparable to other results reported in the literature. Foster et al. (2001), for example, show that net entry contributes to 25 percent of average TFP growth. Although my methodology differs from the one that by Foster et al. employed, my model leads to growth decompositions that are comparable to theirs.

As explained above, market innovation rates are inefficient. To gauge whether there is under or over investment in innovation, I solve for the social planner problem that is subject to the innovation functions of the firms but can dictate to firms what amount of R\&D they should conduct and how much they should produce. Over the long-run, the social planner sets innovation rates that are 9 percentage points higher than the market rates in each sector. Over the long term, the increased innovation rates correspond to a 1.3 percentage point increase in the GDP growth rate. Starting 
from the balanced growth path of the market economy with $2 \%$ GDP growth rate, the social planner immediately increases the GDP growth rate by more than 0.1 percentage point, and then the growth rate gradually increases to its new balanced growth path value of 3.3 percent. However, consumption and GDP follow different trajectories. Like the consumption growth rate, consumption decreases initially as more labor is employed in research. Although the consumption growth rate increases gradually, it remains below its market economy balanced growth path level for some time. Eventually, the consumption growth rate converges with its balanced growth path level of 3.3 percent. Long-run consumption growth outweighs the short-run consumption loss, and the transition from the market economy balanced growth path to the social planner balanced path leads to an almost 15 percent welfare gain to households, as measured in consumption-equivalent terms. Thus, the market is underinvesting in innovation, and a benevolent government can increase the welfare of the household by subsidizing R\&D.

The amount of resources allocated to R\&D at the social planner's balanced growth path is more than three times the market economy resource allocation to innovation. This is similar to what is reported in recent literature that employs related models but different methods. Using Danish data, Lentz and Mortensen (2008) build a model in which firms have persistently different abilities to create higher quality products, and they estimate their model. By using their 2008 paper estimates, Lentz and Mortensen (2015) show that the social planner increases resource allocation to innovation threefold compared to market outcome, which would generate a 21 percent welfare gain, as measured in the tax to social planner consumption. To calculate the welfare gain Lentz and Mortensen compare only the steady states of the market and the social planner economy. The 15 percent welfare gain that I estimate takes 
into account an additional factor: the transition path. Atkeson and Burstein (2015) develop a method to approximate changes in the path of the economy after a policyinduced change has occurred in the innovation intensity of the economy. Their model nests many models related to innovation, including Klette and Kortum (2004). In a calibration that closely resembles Klette and Kortum model, the social planner increases the amount of resources allocated to innovation three times when a lower discount factor is assumed. In consumption equivalent terms, this would generate a 38 percent welfare gain. When the social planner assumes a higher discount factor, he or she increases the innovation intensity of the economy 11 times, and this would increase the welfare of the society 25 times. To characterize the path of the economy after a policy change, Atkeson and Burstein employ a first-order Taylor approximation around the steady state of the market economy. This restricts their method to the analysis of changes in innovation intensity not as large as the social planner would change.

In my model, in a decentralized environment, the government can increase the welfare of society by employing R\&D subsidies and a capital investment subsidy. In my benchmark calibration, subsidizing 82 percent of consumption sector incumbents' R\&D expenditures and 78 percent of investment sector incumbents' R\&D expenditures generates a welfare gain close to that of the social planner. By providing a capital investment subsidy (an output subsidy would generate the same result), the government fixes the distortions in the capital Euler equation, which is a result of the monopoly power enjoyed by investment goods producers. The government also employs an entry subsidy such that the marginal social cost of entrant innovation equals the marginal social cost of incumbent innovation. This result suggests that government can substantially increase the welfare of a society by heavily subsidiz- 
ing innovation with constant rates. The government finances these subsidies with lump-sum taxation of households. Similarly, Grossmann et al. (2013) calculate socially optimum time-dependent $R \& D$ subsidy rate and find that the welfare loss of setting R\&D subsidy rate to its long-run value immediately instead of employing a time-varying $R \& D$ subsidy rate is quite low. They also show that the optimal $R \& D$ subsidy is approximately $81.5 \%$. Both results are in line with my findings. Akcigit et al. (2016) address optimal R\&D policy within a mechanism design framework. They show that when firms are heterogenous in research productivity and there is asymmetric information about research productivity of firms, the optimal subsidy system depends many factors including age of the innovating firms, current and lagged quality of the products of the firms, current and lagged R\&D expenditures of the firms. Since there is no asymmetric information in my model and per-good research productivity of firms are constant within a sector, the optimal R\&D subsidy is same for all the firms in a sector.

Subsidizing the investment sector produces a larger welfare gain than does subsidizing the consumption sector. Applying a given rate of subsidy to just the investment sector raises welfare by twice as much as applying the same subsidy to just the consumption sector. Two factors contribute to the difference in welfare gains. First, each sector has a similar elasticity of innovation with respect to the user cost of R\&D, but the investment sector has a higher innovative step. Hence, any decrease in the user cost would lead to similar changes in innovation rates, but a given change in investment sector innovation leads to a higher consumption growth rate and, hence, a larger welfare gain than would the same amount of change in consumption sector innovation. Second, an increase in the investment sector innovation rate leads to a larger reduction in the price of investment goods. A larger rate of decline in the price 
of investment goods increases the user cost of capital, which results in a lower accumulation of capital. Consequently, consumption production grows more slowly than it would otherwise. During earlier periods, the investment-sector-subsidized economy has a lower consumption than the consumption sector subsidized economy. In other words, the first factor dominates and the welfare gain of subsidizing investment sector $\mathrm{R} \& \mathrm{D}$ is higher.

To achieve welfare-maximizing innovation rates, the government needs to subsidize innovation at roughly 80 percent. This large subsidy rate is mostly the result of two factors. First, there are significant distortions in the economy. As explained above, using related models, Atkeson and Burstein (2015) and Lentz and Mortensen (2015) find substantial under-investment in innovation in the market economy. Similarly, Jones and Williams (2000) find that the market economy typically under-invests in innovation. Second, R\&D subsidies encourage innovation by decreasing the cost of innovation, but they also discourage incumbent innovation by reducing the expected lifetime of an innovation. A higher subsidy leads to a higher firm value, which increases the entry rate. When the entry rate increases, an incumbent firm is more likely to lose its monopoly rents by successfully innovating, and this reduces the expected time period of monopoly rents and the value of innovation (inter-temporal substitution effect increases). Thus, innovation will be discouraged. To compensate for the shortened expected lifetime of innovation, firms needs to be subsidized even more.

I have stressed the importance of firm dynamics and the magnitude of inefficiency differences across the two sectors. It turns out that under the benchmark calibration, the optimal R\&D subsidies to sectors are close to one another. This does not mean that the size of each externality across sectors is equal. On the one hand, the inter- 
temporal spillover effect in the consumption sector is larger than it is in the investment sector. On the other hand, the business-stealing externality is also larger in the consumption sector. Since these two externalities push the innovation rate in opposite directions, the subsidy required to correct these externalities are similar across the two sectors.

This chapter is organized as follows. Section $(1.2)$ describes the model while section (1.3) calibrates the model. Section (1.4) decomposes long-run GDP growth into the contributions of the two sectors and the contributions of entering and incumbent firms. Section (1.5) theoretically characterizes distortions in the economy and numerically compares market outcome to the social planner's equilibrium. Section (1.6) characterizes the subsidy system that would maximize household welfare. Section (1.7) concludes.

\section{$1.2 \quad$ Model}

Time is continuous. There are two sectors in the economy: consumption goods and investment goods. Each sector consists of a unit measure of differentiated goods. In turn, each differentiated good has possibly countably many quality levels. Households rent capital to firms, which are owned by the households. Differentiated goods producers engage in research and development $(\mathrm{R} \& \mathrm{D})$, which results in higher quality levels of existing products in the market.

\subsubsection{Households}

An infinitely-lived representative household chooses time paths of consumption, capital holding, investment in capital, and firm holdings to maximize the discounted sum 
of utility from consumption, $C(t)$,

$$
\max \int_{0}^{\infty} \exp (-\rho t) \ln C_{t} d t
$$

subject to the law of motion for capital stock and a budget constraint:

$$
\begin{aligned}
\dot{K} & =X-\delta K \\
P_{c} C+\left(1-s_{i n}\right) P_{x} X+\dot{A} & =R A+w L+r K-T
\end{aligned}
$$

where $K$ is the capital stock, $X$ is investment, $P_{c}$ is the consumption goods price index and normalized to $1, P_{x}$ is the investment goods price index, $s_{i n}$ is the capital investment subsidy rate, $A$ is total value of the firms, $R$ is the interest rate, $w$ is the wage rate, $L$ is labor supply, $r$ is the rental rate of capital, and $T$ is the lump-sum tax. Henceforth, I will drop time subscripts for notational ease.

Consumption is a CES aggregate of differentiated consumption goods:

$$
C=\exp \left(\int_{0}^{1} \ln \left(\sum_{j=0}^{J(\omega)} q^{j}(\omega) c^{j}(\omega)\right) d \omega\right)
$$

where $q^{j}(\omega)$ is the quality of version $j$ of product $\omega, c^{j}(\omega)$ is the quantity consumed of version $j$ of product $\omega$, and $J(w)$ is the highest quality version of $\omega$. As seen in Equation (1.1), households have perfectly substitutable preferences over the different quality adjusted versions of each product. In equilibrium, this formulation leads to the following demand function: 


$$
c^{j}(\omega)= \begin{cases}\frac{Z}{p^{j}(\omega)} & \text { if } \frac{q^{j}(\omega)}{p^{j}(\omega)} \geq \frac{q^{j^{\prime}}(\omega)}{p^{j^{\prime}}(\omega)} \text { for all } j^{\prime} \\ 0 & \text { otherwise }\end{cases}
$$

where $p^{j}(\omega)$ is the price of version $j$ of product $\omega, Z=P_{c} C$ is the total consumption expenditure, and $P_{c}=\exp \left(\int_{0}^{1} \ln \left(\frac{p(\omega)}{q(\omega)}\right) d \omega\right)=1$.

Investment, $X$, is also a CES aggregate of differentiated investment goods, which are located in a different interval than consumption goods.

$$
X=\exp \left(\int_{0}^{1} \ln \left(\sum_{j=0}^{J(\omega)} q^{j}(\omega) x^{j}(\omega)\right) d \omega\right)
$$

where $x^{j}(\omega)$ is the quantity invested in version $j$ of product $\omega$. The corresponding demand function is

$$
x^{j}(\omega)= \begin{cases}\frac{I}{p^{j}(\omega)} & \text { if } \frac{q^{j}(\omega)}{p^{j}(\omega)} \geq \frac{q^{j^{\prime}}(\omega)}{p^{j^{\prime}}(\omega)} \text { for all } j^{\prime} \\ 0 & \text { otherwise }\end{cases}
$$

where $I=P_{x} X$ is the total investment expenditure, and $P_{x}=\exp \left(\int_{0}^{1} \ln \frac{p(\omega)}{q(\omega)} d \omega\right)$ is the investment price index.

\subsubsection{Firms}

A firm is defined by the set of differentiated goods it produces. Each good is produced by a unique production unit. A firm can own countably many production units. It can expand the set of production units by innovating on other goods it currently does not produce. Similarly, it can lose its existing goods to other innovating firms. 
Furthermore, if a single good producer loses its only production unit, it exits the market. Lastly, entrepreneurs can enter the market by innovating on a good located on the unit interval.

\subsubsection{Innovation by Incumbents}

The amount of research labor a firm hires and the number of goods it produces jointly determine its Poisson innovation arrival rate, $\beta$. Innovation is not directed. The good that is innovated is randomly drawn from a uniform distribution on the unit interval of goods in the market. A firm innovates only in the sector that it currently operates in. An innovation increases the quality of the good by an exogenous factor of $\lambda>1$. This factor is the quality ladder step size and represents the innovativeness of a firm. Throughout the paper, the term innovativeness will be used to signify the factor by which the quality of a product increases after a successful innovation. More innovative firms can increase the quality of a good by a larger factor. The level of innovativeness varies by sector but is invariant across firms within each sector. After a successful innovation, the innovator and the firm which has the blueprints of producing the second highest quality version (runner-up) of the good engage in Bertrand competition. The innovator charges a price equal to $\lambda$ times marginal cost of production of second highest quality version of the good. Since consumers have infinitely elastic preferences over the quality adjusted varieties of a good, the innovator takes over the market. The innovator expands by one good, the runner-up shrinks by one good.

A firm currently producing $m$ goods and hiring $l_{R}$ units of labor for the purpose of research innovates at a rate $\varphi\left(m, l_{R}\right)=\beta$, where $\varphi(\cdot)$ is a constant returns to scale 
production function, increasing in both arguments, and strictly concave in $l_{R}$. Firms with experience in innovation, particularly those that retain their products despite innovation by other firms, are better at producing ideas. The number of goods in the production function is a proxy for a firm's experience in innovation.

\subsubsection{Consumption Goods Producers}

I define the problem of a differentiated consumption good producer in two steps. First, I define the static problem: how much to produce, and demand for factor inputs. After solving this problem and establishing the profit from production, I turn to the dynamic problem: how much to invest in $R \& D$ to maximize the value of the firm.

Each production unit of a firm has a Cobb-Douglas production function with capital elasticity $\alpha$. Production of each unit is independent of other production units a firm may possess. Hence, each production unit solves the following cost minimization problem:

$$
\min _{l_{c}, k_{c}} w l_{c}+r k_{c} \quad \text { subject to } \quad k_{c}^{\alpha} l_{c}^{1-\alpha}=c
$$

where $w$ and $r$ are the market wage and capital rental rates. The resulting cost function, $C((w, r), c)=\frac{r^{\alpha} w^{1-\alpha} c}{\tilde{\alpha}}$, with $\tilde{\alpha} \equiv \alpha^{\alpha}(1-\alpha)^{1-\alpha}$, is common across all the production units in a sector. As a result, Bertrand competition yields a price $p^{j}=$ $\lambda_{c} \frac{r^{\alpha} w^{1-\alpha}}{\tilde{\alpha}}$ for differentiated product $j$. Using this price and the demand function for differentiated goods yields the profit of a differentiated good producer:

$$
\pi=p c-C((w, r, c))=\left(1-\frac{1}{\lambda_{c}}\right) Z
$$


Note that profits do not vary across differentiated goods in a sector.

Turning to the dynamic problem, I use the profit function in (1.5) to derive the firm's value function, which can be expressed either as a function of the level of research labor or, more conveniently, the level of innovation arrival rate per good. Let $\phi(\beta, m)$ denote the level of $l_{R}$ implicitly defined by $\varphi\left(m, l_{R}\right)=\beta$. Since $\varphi(\cdot)$ is strictly increasing in $l_{R}$, and homogenous of degree one, $\phi(\cdot)$ is well-defined and homogenous of degree one and convex in $\beta$. Set $\phi_{c}\left(b_{c}, m\right)=m \chi_{c} b_{c}^{\gamma}$, where $b_{c}=\beta / m$, and $\chi_{c}>0$ is a scale parameter.

The Bellman equation of the firm on the balanced growth path is

$$
\begin{aligned}
R V(m, Z) & =\max _{b_{c} \geq 0}\left\{\left(1-\frac{1}{\lambda_{c}}\right) m Z-\left(1-s_{c}^{i}\right) w \phi_{c}\left(b_{c}, m\right)+\frac{\partial V(m, Z)}{\partial Z} \dot{Z}\right. \\
& \left.+m b_{c}[V(m+1, Z)-V(m, Z)]+m \tau_{c}[V(m-1, Z)-V(m, Z)]\right\}
\end{aligned}
$$

where $s_{c}^{i}$ is the rate of $\mathrm{R} \& \mathrm{D}$ subsidy for the consumption sector incumbents, and $\tau_{c}$ is the equilibrium Poisson innovation arrival rate in the consumption sector. Given that firm profits, and R\&D expenditures are linear in the number of goods, I conjecture that $V(m, Z)=\nu_{c} m Z$ for some $\nu_{c}>0$ and verify this claim. Inserting the guess yields

$$
R \nu_{c} m Z=m\left(1-\frac{1}{\lambda_{c}}\right) Z-\left(1-s_{c}^{i}\right) w m \chi_{c} b_{c}^{\gamma}+\nu_{c} m Z g_{Z}+m b_{c} \nu_{c} Z-m \tau_{c} \nu_{c} Z
$$

where $b_{c}$ is the optimal innovation intensity, and $g_{Z} \equiv \frac{\dot{Z}}{Z}$ is the growth rate of household consumption expenditure.

Rearranging and simplifying the above equation leads to the following solution to 
the Bellman eqution:

$$
\left(R-g_{Z}+\tau_{c}-b_{c}\right) \nu_{c}=\left(1-\frac{1}{\lambda_{c}}\right)-\left(1-s_{c}^{i}\right) \chi_{c} b_{c}^{\gamma} \frac{w}{Z} .
$$

The first order condition for innovation arrival rate per product is:

$$
\left(1-s_{c}^{i}\right) w \gamma \chi_{c} b_{c}^{\gamma-1}=\nu_{c} Z
$$

Equation (1.7) establishes that innovation arrival rate per product is independent of firm size or the number of goods a firm produces. In my solution of the stationary equilibrium, the growth rate of consumption expenditures, $g_{Z}$, is constant and equal to the growth rate of wages, $g_{w}$. Appendix A.2 solves the problem and shows the equality of $g_{Z}$ and $g_{w}$. All this, together with Equation (1.6), verify that the value function is indeed linear in $m$.

Entrepreneurs can enter the market by innovating on a product. Like incumbents, they hire research labor to develop better qualities of products. An entrepreneur must hire $\xi_{c}\left(z_{c}, \bar{z}_{c}\right) \equiv \psi_{c} \chi_{c} z_{c} \bar{z}_{c}^{\gamma-1}$ units of labor to secure a $z_{c}$ Poisson innovation rate, where, $\psi_{c}>0$ is a parameter to differentiate the cost of incumbent and entrant innovation, and $\bar{z}_{c}$ is the entry rate in the market. As more entrants try to enter to the market, it requires more effort to develop a successful product. This formulation is a reduced form of the limited availability of venture capital to entrepreneurs. The value of entry is therefore

$$
R V_{E}=\max _{z_{c} \geq 0}\left\{-\left(1-s_{c}^{e}\right) w \xi_{c}\left(z_{c}, \bar{z}_{c}\right)+z_{c}\left[V(1, Z)-V_{E}\right]\right\}
$$

where $s_{c}^{e}$ is entry subsidy rate (i.e. entrant innovation subsidy) in the consumption 
sector. Free entry drives down the value of entry to zero. Hence, in equilibrium

$$
\left(1-s_{c}^{e}\right) w \psi_{c} \chi_{n} \bar{z}_{c}^{\gamma-1}=V(1, Z)
$$

\subsubsection{Investment Goods Producers}

Firms in this sector share the same Cobb-Douglas production function with capital elasticity $\alpha$. The profit of a production unit, $\pi=\left(1-\frac{1}{\lambda_{x}}\right) I$, is derived in a manner analogous to that of the consumption goods producers. The value of a firm currently producing $m$ goods, $V(m, I)$, solves the Bellman equation

$$
\begin{aligned}
R V(m, I) & =\max _{b_{x} \geq 0}\left\{\left(1-\frac{1}{\lambda_{x}}\right) m I-\left(1-s_{x}^{i}\right) w \phi_{x}\left(b_{x}, m\right)+\frac{\partial V(m, I)}{\partial I} \dot{I}\right. \\
& \left.+m b_{x}[V(m+1, I)-V(m, I)]+m \tau_{x}[V(m-1, I)-V(m, I)]\right\}
\end{aligned}
$$

where $s_{x}^{i}$ is the R\&D subsidy rate for the investment sector incumbent firms. Guessing and verifying that the value function of investment goods producers is also linear in $m$, the following equations characterize the value function and first order condition for the optimal innovation arrival rate per product:

$$
\begin{aligned}
& \left(R-g_{I}+\tau_{x}-b_{x}\right) \nu_{x}=\left(1-\frac{1}{\lambda_{x}}\right)-\left(1-s_{x}^{i}\right) \chi_{x} b_{x}^{\gamma} \frac{w}{I} \\
& \left(1-s_{x}^{i}\right) w \gamma \chi_{x} b_{x}^{\gamma-1}=\nu_{x} I .
\end{aligned}
$$

Entrants, on the other hand, have the following problem:

$$
R V_{E}=\max _{z_{x} \geq 0}\left\{-\left(1-s_{x}^{e}\right) w \xi_{x}\left(z_{x}, \bar{z}_{x}\right)+z_{x}\left[V(1, I)-V_{E}\right]\right\}
$$


where $s_{x}^{e}$ is the entry subsidy in investment sector. Free entry implies

$$
-w \psi_{x} \chi_{x} \bar{z}_{x}^{\gamma-1}=V(1, Z)
$$

\subsubsection{Equilibrium}

A symmetric balanced growth path competitive equilibrium is defined by a tuple of firm decisions $\left\{k_{i, t}, l_{i, t}, l_{R, i, t}, b_{i, t}, z_{i, t}, \tau_{i, t}, c_{t}, x_{t}\right\}$, where $i=c, x$ represents consumption and investment sectors, a tuple of household decisions $\left\{c_{t}, x_{t}, C_{t}, X_{t}, K_{t}\right\}$, a tuple of prices $\left\{w_{t}, r_{t}, R_{t}, p_{c, t}, p_{x, t}, P_{c, t}, P_{x, t}\right\}$, aggregate expenditures $\left\{Z_{t}, I_{t}\right\}$, average quality levels in each sector, $\left\{Q_{c, t}, Q_{x, t}\right\}$, and value of production units per aggregate expenditure in a firm's sector, $\left\{\nu_{c}, \nu_{x}\right\}$. In equilibrium the following conditions hold.

- $\left\{p_{c}, p_{x}\right\}$ are the Bertrand equilibrium prices of highest quality products.

- Given prices of differentiated goods and household demand functions $(1.2)$ and (1.4) $k_{c}, l_{c}$ and $k_{x}, l_{x}$ solve the firm cost-minimization problems in the consumption and investment sectors.

- Given prices and nominal aggregate expenditures, $\left\{\nu_{c}, b_{c}, z_{c}\right\}$ solve equations (1.6), (1.7), 1.8 for $i=c$, and $\left\{\nu_{x}, b_{x}, z_{x}\right\}$ solve equations (1.9), (1.10, (1.11) for $i=x$.

- Innovation rate in a sector is equal to sum of incumbent and entrant innovation rates: $\tau_{i, t}=z_{i, t}+b_{i, t}$, where $i=c, x$.

- Given prices, $\left\{c_{t}, x_{t}, C_{t}, X_{t}, K_{t}\right\}$ are the balanced growth path values of the household optimization problem. 
- The labor market clears: $l_{c}+l_{x},+\chi_{c} b_{c}^{\gamma}+\chi_{x} b_{x}^{\gamma}+\psi_{c} \chi_{c} z_{c}^{\gamma}+\psi_{x} \chi_{x} z_{x}^{\gamma}=L$,

- The capital market clears: $K_{t}=k_{c, t}+k_{x, t}$,

- Nominal expenditures, $\{Z, I\}$, grow at the same rate.

- Average quality levels of industries are $Q_{c}=\exp \left(\int_{0}^{1} \ln (q(\omega)) d \omega\right)$, $Q_{x}=\exp \left(\int_{0}^{1} \ln (q(\omega)) d \omega\right)$.

This equilibrium is discussed in detail in Appendix A.2.

\subsection{Calibration}

I classify industries into consumption goods producers and investment goods producers following the methodology applied by Huffman and Wynne (1999). Specifically, I classify an industry as a consumption goods producer if, according to the economy's input-output table, household consumption of the industry output is larger than sum of the industry output added to inventory and output used by other firms. Similarly, investment goods industries are those whose output is used mostly by other firms. Appendix A.1 specifies the industries in each group.

Table 1.1 reports the parameters that are calibrated independently from the data or taken from other papers. A unit length of time in the model is considered as a year in the data. The elasticity of output with respect to capital is chosen as 0.33. The depreciation rate, $\delta$, is calibrated to have a $5 \%$ annual deprecation rate [KLEMS data on U.S.], and the discount rate is targeted to have a 0.97 annual discount factor.

To calibrate the curvature of the $\mathrm{R} \& \mathrm{D}$ cost function, $\gamma$, I target price elasticity of R\&D with respect to its user cost estimated by Bloom et al. (2002). They estimate 
Table 1.1: Externally calibrated parameters

\begin{tabular}{lcc}
\hline \hline & Parameter & Value \\
\hline Elasticity of output w.r.t capital & $\alpha$ & .33 \\
Depreciation Rate & $\delta$ & .06 \\
Discount Rate & $\rho$ & .03 \\
Curvature of R\&D cost function & $\gamma$ & 2.5 \\
R\&D subsidy, consumption incumbents & $s_{c}^{i}$ & .2 \\
R\&D subsidy, investment incumbents & $s_{x}^{i}$ & .2 \\
\hline
\end{tabular}

both short-run and long-run elasticity of R\&D with respect to its user cost. Short-run elasticity, the immediate effect of user cost changes, is estimated as 0.35 . This value corresponds to a $\gamma$ value of 3.85 in my model. However, firms' R\&D expenditures are highly persistent. A change in user cost at the current period affects $R \& D$ in all subsequent periods. Bloom at al. estimate a long-run elasticity, sum of $R \& D$ changes in all subsequent periods, as approximately 1 . This elasticity corresponds to a $\gamma$ value of 2 in my model. However, neither of these estimates correspond exactly to my model. In the model, firms make $R \& D$ decision for each period and get the benefit of $R \& D$ immediately. In reality, firms commit to $\mathrm{R} \& \mathrm{D}$ for certain periods of time, but not indefinitely. Therefore, I choose $\gamma=2.5$, a number that corresponds approximately to midway between the short-run and long-run elasticities. R\&D subsidy rates for incumbent firms in the two sectors are chosen as 0.2 following the $R \& D$ tax credit rate in the US Bloom et al. (2002)].

Other parameters of the model are calibrated by using the implications of the model on firm entry and expansion rates. The innovation rate by entrants corresponds to the firm entry rate - the measure of entering production units over the total measure of production units in the sector. The innovation rate by incumbents corresponds to firm expansion rates - the measure of production units captured by 
Table 1.2: Targets

\begin{tabular}{llcc}
\hline \hline & Variable & Data & Model \\
\hline Entrant innovation rate, consumption & $z_{c}$ & .06 & .06 \\
Entrant innovation rate, investment & $z_{x}$ & .04 & .04 \\
Incumbent innovation rate, consumption & $b_{c}$ & .1 & .1 \\
Incumbent innovation rate, investment & $b_{x}$ & .09 & .09 \\
Consumption growth rate & $g_{C}$ & .02 & .02 \\
Growth rate of investment good prices & $g_{P_{x}}$ & -.02 & -.02 \\
relative to consumption good prices & & & \\
\hline
\end{tabular}

incumbent firms over the total measure of production units in the sector. Further, since each production unit in a sector employs the same amount of labor, the innovation rate by entrants is equal to the number of jobs created by entering firms over the total employment in that industry (job creation rate by birth). Similarly, the innovation rate by incumbents is equal to the number of jobs created by expanding firms over the total employment in that industry, which is called job creation rate by expansion. Statistics of United States Businesses (SUSB) provides job creation rates by birth and job creation by expansion of establishments for 4 digit NAICS. I use SUSB data from 1999 to 2012 to compute average job creation rates by birth and expansion for the industry classification of this paper. The first row of Table 1.2 shows these rates which I target as innovation by entrants and incumbents in each sector.

The model also has implications on the growth rates of consumption and the relative price of investment goods, equations 1.12 and 1.13 . Technological progress in each industry contributes to the growth rate of consumption, whereas the growth rate of the relative price of investment goods depends on the difference of technological 
Figure 1.1: Industry Dynamics
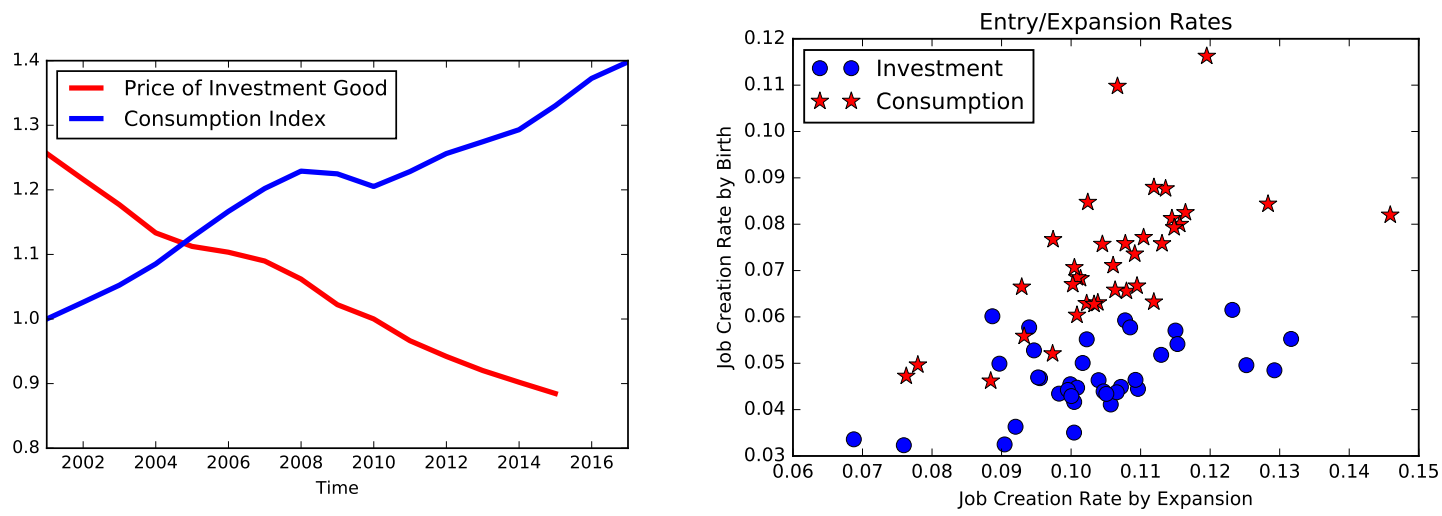

progress in each sector.

$$
\begin{aligned}
& g_{C}=\tau_{c} \ln \lambda_{c}+\frac{\alpha}{1-\alpha} \tau_{x} \ln \lambda_{x} \\
& g_{P_{x}}=\tau_{c} \ln \lambda_{c}-\tau_{x} \ln \lambda_{x}
\end{aligned}
$$

The consumption growth rate is targeted as $2 \%$, the historical average of the US consumption growth rate, depicted in the left panel of Figure 1.1. The growth rate of the price of quality adjusted investment goods is approximately $-2 \%$. Gordon (1990), Cummins and Violante (2002) and DiCecio (2009)] Therefore, the innovativeness of sectors $\left(\lambda_{c}\right.$ and $\left.\lambda_{x}\right)$ is identified using Equations (1.12) and (1.13) and target rates for the consumption growth rate, the change in the relative price of investment goods, and the innovation rates in each industry.

The other parameters of the model seen in Table 1.3 are calibrated to make the model moments match with the target moments in the data. The relative costs of entry $\psi_{x}, \psi_{c}$, in each sector are identified by job creation by birth over job creation by expansion rate in these industries. The right panel of Figure 1.1 shows the job creation rates by birth and expansion for consumption and investment goods sec- 
Table 1.3: Internally calibrated parameters

\begin{tabular}{lcc} 
& Parameter & Value \\
\hline Quality ladder step size, investment & $\lambda_{x}$ & 1.23 \\
Quality ladder step size, consumption & $\lambda_{c}$ & 1.04 \\
R\&D cost function parameter, investment & $\chi_{x}$ & 10.93 \\
R\&D cost function parameter, consumption & $\chi_{c}$ & 5.73 \\
Entry cost function parameter, investment & $\psi_{x}$ & 6.75 \\
Entry cost function parameter, consumption & $\psi_{c}$ & 4.30 \\
\hline
\end{tabular}

tor. Each star or circle is an annual observation from the data. Stars represent the consumption goods industry observations and circles the investment goods industry observations. As seen in the graph, job creation rate by birth over job creation by expansion is higher in consumption industries. This data results in a lower $\psi$ value of the consumption sector. Overall, the results of the calibration exercise indicate that: 1) the quality ladder step size of investment goods is higher than that of consumption goods $\left.\left(\lambda_{x}>\lambda_{c}\right), 2\right)$ innovation in the investment goods sector is more costly $\left(\chi_{x}>\chi_{c}\right)$. 3) innovation is costlier for entrants $\left(\psi_{x}, \psi_{c}>1\right)$, and 4$)$ entry is more costly in the investment sector $\left(\psi_{x}>\psi_{c}\right)$.

\subsection{Growth Decomposition}

Consumption growth in the long-run is a result of innovative activities in the two sectors. As described in Equation 1.12), consumption growth rate can be decomposed into contributions of technological progress in consumption goods and technological progress in investment goods. Using the definition of the total innovation rate, which is the sum of entrant innovation and incumbent innovation, consumption growth rate 
can be further decomposed into contributions of entrants and incumbents:

$$
\begin{aligned}
& g_{C}=\left(z_{c}+b_{c}\right) \ln \lambda_{c}+\frac{\alpha}{1-\alpha}\left(z_{x}+b_{x}\right) \ln \lambda_{x} \\
& g_{C}=\underbrace{z_{c} \ln \lambda_{c}}_{\substack{\text { Consumption } \\
\text { Entrants }}}+\underbrace{b_{c} \ln \lambda_{c}}_{\substack{\text { Consumption } \\
\text { Incumbents }}}+\underbrace{\frac{\alpha}{1-\alpha} z_{x} \ln \lambda_{x}}_{\begin{array}{c}
\text { Investment } \\
\text { Entrants }
\end{array}}+\underbrace{\frac{\alpha}{1-\alpha} b_{x} \ln \lambda_{x}}_{\begin{array}{c}
\text { Investment } \\
\text { Incumbents }
\end{array}} .
\end{aligned}
$$

Equation (1.14) decomposes the growth rate by sectors and entrants/incumbents. Table 1.4 shows each element's contribution as a percentage of the consumption growth rate. The investment sector contributes $66 \%$ percent of growth, whereas the consumption sector contributes $34 \%$. The contribution of the investment sector in my estimates is comparable to estimates of Sakellaris and Wilson (2004), who empirically find that embodied technological change in investment goods contributes two thirds of macroeconomic growth.

Table 1.4: Consumption Growth Decomposition

\begin{tabular}{l|cc|c} 
& Consumption & Investment & Total \\
\hline Entrant & $13 \%$ & $20 \%$ & $33 \%$ \\
Incumbent & $21 \%$ & $46 \%$ & $67 \%$ \\
\hline Total & $34 \%$ & $66 \%$ &
\end{tabular}

Entrants contribute approximately one third to growth. Remember, in the model, the innovativeness of entrants and incumbents are the same. Hence, the difference of entrants and incumbents in terms of contribution to growth stems mainly from different entry and expansion rates. Similar to my results, by using the Census of Manufacturers data from 1977 to 1987, Foster et al. (2001) show that net entry contributes one quarter of multi-factor productivity growth. Overall, investment sector incumbents contribute the most to growth and consumption sector entrants contribute the least. Intuitively, most of the growth comes from companies producing better machines, 
and less comes from consumption sector entrants like new restaurants.

\subsection{Optimality of Innovation}

As a characteristic of Schumpeterian creative-destruction type models, the competitive equilibrium innovation rate may not be socially optimal. An innovating firm improves the quality of an existing good, destroys the profit accrued by the incumbent producer and gains monopoly power on production of the product that it innovated. While deciding the amount of R\&D to conduct, it considers the monopoly profits that it will accrue until another firm innovates on that good and captures the product. However, the social benefit of an innovation goes on forever since every innovator improves the quality upon the existing quality level. Also, innovators ignore the profit loss of the existing producer of the good. Therefore, the competitive equilibrium innovation rate is generically inefficient. After defining the social planner problem, I will discuss each externality further in Section 1.5.2,

In order to identify how the externalities affect the economy, I define and solve the social planner's problem. Then, I compare the competitive equilibrium first order conditions with the social planner first order conditions, and discuss the differences caused by externalities.

\subsubsection{Social Optimum}

The social planner problem (SP) can be divided into two parts: 1) a static problem where a given level of total innovation in a sector is allocated to entrants and incumbents, and 2) a dynamic problem where the time paths of labor, capital and innovation are determined. 
In the static problem, the social planner minimizes the research cost of a fixed aggregate innovation in a sector by choosing incumbent entry and innovation rates:

$$
\min _{z_{i}, b_{i}} \psi_{i} \chi_{i} z_{i}^{\gamma}+\chi_{i} b_{i}^{\gamma} \text { subject to } z_{i}+b_{i}=\tau_{i}
$$

where $z_{i}$ is the entry rate, $b_{i}$ is the innovation rate by incumbents, $\tau_{i}$ is the aggregate innovation rate, and $i=c, x$ represents sectors. Note that the social planner takes into account the externality created by entrants on each other. The resulting cost function (in labor units) for a sector is

$$
C_{i}\left(\tau_{i}\right)=\frac{\psi_{i} \chi_{i} \tau_{i}^{\gamma}}{\left(1+\psi_{i}^{1 /(\gamma-1)}\right)^{\gamma-1}}
$$

The economy-wide research cost function is the sum of innovation costs across sectors,

$$
C\left(\tau_{c}, \tau_{x}\right)=\frac{\psi_{c} \chi_{c} \tau_{c}^{\gamma}}{\left(1+\psi_{c}^{1 /(\gamma-1)}\right)^{\gamma-1}}+\frac{\psi_{x} \chi_{x} \tau_{x}^{\gamma}}{\left(1+\psi_{x}^{1 /(\gamma-1)}\right)^{\gamma-1}}
$$

Using the research labor cost function found in the static problem, the social planner then maximizes the discounted sum of utility from consumption:

$$
\max \int_{0}^{\infty} e^{-\rho t} \ln \left(K_{c, t}^{\alpha} L_{c, t}^{1-\alpha} Q_{c, t}\right) d t \quad \text { subject to }
$$

the resource constraints of capital, $K_{c, t}+K_{x, t}=K_{t}$, and labor, $L_{c, t}+L_{x, t}+C\left(\tau_{c, t}, \tau_{x, t}\right) \leq$ 1, the law of motion for capital stock, $\dot{K}_{t}=K_{x, t}^{\alpha} L_{x, t}^{1-\alpha} Q_{x, t}-\delta K_{t}$, the average quality levels in each sector, $Q_{c, t}=\exp \left(\int_{0}^{1} \ln \left(q_{t}(\omega)\right) d \omega\right), Q_{x, t}=\exp \left(\int_{0}^{1} \ln \left(q_{t}(\omega)\right) d \omega\right)$, and laws of motion for the technology index of the consumption sector, $\frac{\dot{Q}_{c, t}}{Q_{c, t}}=\tau_{c, t} \log \lambda_{c}$, 
and the investment sector, $\frac{\dot{Q}_{x, t}}{Q_{x, t}}=\tau_{x, t} \log \lambda_{x}$.

\subsubsection{Distortions}

Innovative activity leads to various distortions in the market equilibrium conditions relative to the social optimum. First, an improvement in the quality level of a good gives market power to the innovator, i.e. she can charge a markup over the marginal cost of production. Second, quality improvements occur over existing innovations ('standing on the shoulders of giants'). Hence, an innovation increases the quality level of a good forever, but the innovator gets the benefit for a limited time, until the next innovation on the good. Third, innovation destroys the profit accruing to the incumbent ('business stealing'). Fourth, the cost of entry into the market by an entrepreneur increases with the measure of total innovative activity by entrants. The first order condition for innovation rates (denoted with by '^, ) in competitive equilibrium, and first order condition for social planner innovation (denoted with '* ') are as follows:

$$
\begin{aligned}
& c^{\prime}(\hat{b}) w=\frac{1(\pi-c(\hat{b}) w)}{\rho+\tau-b}, \\
& c^{\prime}\left(b^{*}\right) F_{L}(K, L, Q)=\frac{\ln (\lambda) F(K, L, Q)}{\rho},
\end{aligned}
$$

where $c(\cdot)$ is the R\&D cost function defined in Equation 1.15, and $F(\cdot)$ sector-level production function. For the sake of simplicity of notation, I dropped sector subscripts. Equations (1.16) and 1.17 hold for each sector. Following Aghion and Howitt (1992), I compare Equations (1.16) (competitive equilibrium first order con- 
dition) and (1.17) (social planner FOC) to understand the effect of these distortions on innovation level. These FOCs equate the marginal cost of innovation to the discounted benefit of innovation. The marginal cost of the innovation in the competitive equilibrium is $c^{\prime}(b) w$, while the marginal cost in the $\mathrm{SP}$ problem is $c^{\prime}(b) F_{L}(K, L, Q)$. Since firms have monopoly power, the marginal product of labor may differ from the wage rate. This monopoly-distortion effect causes the competitive equilibrium innovation level to exceed the SP level (Aghion and Howitt (1992)).

Second, the private flow benefit of innovation is the monopoly profit minus research cost, $\pi-c(b) w$, whereas the social benefit is total output $F(K, L, Q)$, so that $b^{*}$ exceeds $\hat{b}$ [Approbriability]. Third, as a result of innovation, the monopolist takes over the market for the good, and it does not consider the loss the incumbent incurs. Hence, we have ' 1 ' in front of $\pi$. However, the social planner considers the change in utility as a result of collective innovation. Hence it has $\log \lambda$ in front of $F(\cdot)$. This business-stealing effect leads to a higher level of private innovation. Fourth, the private innovator accrues the benefits as long as she has the monopoly power over the good. Therefore, she discounts the profits at a rate $\rho+\tau-b$. However, the benefits of innovation accrue to society forever, since the quality increase lasts eternally. This inter-temporal spillover effect yields higher social planner innovation levels.

The Euler equations in the market economy and social planner are

$$
\begin{aligned}
& \frac{1}{\lambda_{x}} \alpha \hat{K}_{x}^{\alpha-1} \hat{L}_{x}^{1-\alpha} Q_{x}-\delta-\rho=\frac{1}{1-\alpha} \hat{\tau}_{x} \ln \lambda_{x} \\
& \alpha K_{x}^{* \alpha-1} L_{x}^{* 1-\alpha} Q_{x}-\delta-\rho=\frac{1}{1-\alpha} \tau_{x}^{*} \ln \lambda_{x} .
\end{aligned}
$$

Monopoly pricing distorts the price of the investment good, leading to differences in the Euler Equations (1.18) and 1.19): $1 / \lambda_{x}$ appears in front of the marginal product 
of capital in the investment goods sector in competitive equilibrium, but not in the social planner equation. This distortion leads to less private capital than the social optimum. However, innovation in investment goods also affects the change in relative price of investment goods. The higher the innovation, the greater the decline in price of investment goods. The greater pace of decline in the price of investment goods makes acquiring capital in initial periods costlier. Hence, regimes that have a higher innovation in investment goods have lower level of capital.

Though it is not the focus of this paper, there is another externality created by the entry process, namely entrants do not internalize the extra entry cost they impose on other entrants. Equation 1.20 shows the competitive equilibrium first order condition for allocation of innovation between entrants and incumbents whereas Equation (1.21) shows the social planner allocation of innovation. In the social planner allocation marginal costs of entry and incumbent innovations are equated, but not in the competitive equilibrium. This leads to a more than optimal entry rate.

$$
\begin{aligned}
& \psi \chi \hat{z}^{\gamma-1}=\gamma \psi \chi \hat{b}^{\gamma-1} \\
& \gamma \psi \chi z^{* \gamma-1}=\gamma \psi \chi b^{* \gamma-1}
\end{aligned}
$$

Lastly, since capital and labor markets are competitive, the only distortion in the factor demand equations comes from monopoly pricing of the goods. Equating relative factor prices across sectors, I get the undistorted capital labor ratios. Equation 1.22 is identical in market equilibrium and in the social planner allocation:

$$
\frac{1-\alpha}{\alpha} \frac{K_{x}}{L_{x}}=\frac{1-\alpha}{\alpha} \frac{K_{c}}{L_{c}} .
$$




\subsubsection{Under Investment in Innovation}

Of the distortions identified above, appropriability and inter-temporal spillover effects cause the economy to under-invest in innovation whereas business stealing and monopoly distortion cause the economy to over-invest in innovation. Whether the economy under-or over-invest in innovation depends on the parameters of the model. In this economy, it is under-investment as shown in Table 1.5. Column 1 shows the competitive equilibrium consumption growth rate, innovation rates in sectors and

discounted capital stock, $\tilde{K}=\frac{K}{Q_{x}^{1 / 1-\alpha}}$, which is the capital stock level at the steady state of the economy where variables are discounted accordingly with the technology indices. Column 2 shows the social planner values. Socially optimal innovation rates in both sectors are 9 percentage points higher than competitive equilibrium rates. These higher innovation rates make the economy grow 1.3 percentage point faster under the social planner. In a similar exercise, using a Schumpeterian creative destruction model whose parameters are estimated using Danish firm level data, Lentz and Mortensen (2015) find that the optimal growth rate is twice as much as the competitive equilibrium growth rate $]^{1}$

Later, I discuss the welfare implications of R\&D subsidies that push the economy towards social planner allocations. The change in consumption growth rate will play an important role in generating welfare gain. The other important factor that needs to be analyzed is capital stock. Removing the monopoly distortion in the capital Euler equation (1.18) leads to higher capital accumulation, whereas higher user cost of capital, resulting from higher innovation in investment goods, would result in lower accumulation of capital. Here, the latter force dominates and steady state

\footnotetext{
${ }^{1}$ They consider a model where firms in a sector have different innovativeness which evolve according to a Markov Process.
} 
capital stock of the social planner is lower than capital stock in the market economy. A transition of the economy from competitive equilibrium innovation levels to social planner innovation levels would cause labor allocated to consumption good production to decrease. On the other hand, if the amount of capital invested also decreases then some of the labor allocated to investment good production can be used in consumption good production or research. This will create extra welfare gain in the economy.

Table 1.5: Competitive Equilibrium vs Social Planner

\begin{tabular}{cccccc} 
& \multicolumn{2}{c}{$\mathrm{CE}$} & & \multicolumn{3}{c}{$\mathrm{SP}$} \\
\cline { 2 - 2 } \cline { 5 - 6 } & & & $\mathrm{CE} \tau_{c}$ & $\mathrm{CE} \tau_{x}$ \\
\hline$g_{C}$ & 0.020 & & 0.033 & 0.030 & 0.025 \\
$\tau_{c}$ & 0.160 & & 0.252 & 0.160 & 0.277 \\
$\tau_{x}$ & 0.130 & & 0.219 & 0.230 & 0.130 \\
$\tilde{K}$ & 3.027 & & 2.390 & 2.477 & 3.671 \\
\hline
\end{tabular}

Notes: Column 1 (CE) shows the competitive equilibrium values, column 2 (SP) the social planner values, column $3\left(\mathrm{CE} \tau_{c}\right)$ the social planner values when she is restricted to have competitive equilibrium innovation rate in consumption sector, and column $4\left(\mathrm{CE} \tau_{x}\right)$ when the social planner is restricted to have competitive equilibrium innovation rate in investment sector.

After substituting the functional forms and rearranging Equations (1.16) and (1.17), we get Equations (1.23) and (1.24) below. Now, inter-temporal spillover effect is the difference between the denominators of the right-hand sides of the equations, and the combination of appropriability, business-stealing, and monopoly distortion effects is represented by the difference between the numerators of the right-hand sides of equations. 


$$
\begin{aligned}
\frac{1}{1-\gamma} \chi_{j} b_{j}^{\gamma /(1-\gamma)} & =\frac{\frac{\left(\lambda_{j}-1\right) L_{j}}{(1-\alpha)\left(1-s_{i j}\right)}-\chi_{j} b_{j}^{1 /(1-\gamma)}}{\rho+z_{j}} \\
\frac{1}{1-\gamma} \chi_{j} b_{j}^{\gamma /(1-\gamma)} & =\frac{\frac{\ln \lambda_{j} L_{j}}{1-\alpha}}{\rho}, j=c, x .
\end{aligned}
$$

To understand the relative importance of the distortions in the two sectors, I conduct the following exercise which is reported in Table 1.6. When only intertemporal spillover is corrected, and holding the other values fixed, the incumbent innovation rate in the consumption-goods sector doubles and becomes more than the socially efficient innovation rate. The incumbent innovation rate in the investmentgoods sector also increases substantially, but it does not go above the social planner level. When business-stealing is corrected, the incumbent innovation rate in the consumption-goods sector declines 90 percent to 0.01 . Whereas, incumbent innovation rate in investment-goods sector reduces by 66 percent to 0.03 . This exercise shows that both inter-temporal spillover and business-stealing effects are stronger in the consumption-goods sector.

Table 1.6: Incumbent Innovation Rates

\begin{tabular}{lcc}
\hline \hline & Consumption & Investment \\
\hline Competitive equilibrium & .10 & .09 \\
Correct inter-temporal spillover & .21 & .16 \\
Correct business-stealing & .01 & .03 \\
Social Planner & .18 & .17 \\
\hline
\end{tabular}

Notes: Competitive equilibrium incumbent firm innovation rates and when certain externalities are corrected.

To gauge the relative importance of innovations in the two sectors, I conduct the 
following exercises which are shown in columns $3\left(\mathrm{CE} \tau_{c}\right)$ and $4\left(\mathrm{CE} \tau_{x}\right)$ of Table 1.5. In the exercise depicted in column 3, I solve the social planner problem while constraining the innovation rate in the consumption sector to the competitive equilibrium value. Now, the social planner allocates more labor to innovative activity in the investment sector and reaches a consumption growth rate close to the unconstrained problem rate. However, in a similar exercise where the investment sector innovation rate is constrained to its competitive equilibrium level instead of the consumption sector, the consumption growth rate is 0.8 percentage points lower than the social planner rate (reported in column 4). Though the social planner increases the innovation rate in the consumption sector, it is not enough to compensate purge in the investment sector innovation. These exercises point out that the socially optimum growth rate is significantly higher than the growth rate in the market economy. Also, it is the under-innovation in the investment sector that leads to a large gap between competitive equilibrium and the socially optimum growth rates.

The change in steady state capital stock level is also in line with the analysis comparing the competitive equilibrium with the social planner. When restricting the investment sector innovation to CE levels, steady state capital stock increases. Holding the innovation rate fixed in this sector maintains the user cost of capital at the market economy level. However, the social planner still corrects the monopoly pricing of the investment good. As a result, steady state capital stock increases relative to the competitive equilibrium. However, when the consumption sector innovation is restricted, and the social planner is free to the choose investment sector innovation, capital stock is less than the competitive equilibrium level but higher than the social planner level. The former is expected. The second one may seem counter to my arguments above. The investment sector innovation rate in the constrained 
social planner's solution is higher than the unconstrained social planner, and hence the user cost of capital is higher. We would expect a lower accumulation of capital, but we observe a higher accumulation of capital. The reason is: a reduction in the consumption sector innovation frees up some labor which can be allocated to investment good production. This increased labor in the sector leads to higher marginal product of capital. That is why we see an increase in capital accumulation relative to the unconstrained social planner problem. I will return to the importance of capital accumulation when I discuss the welfare implications of innovation subsidies.

Analyzing just the balanced growth path does not give the whole picture of welfare and growth implications of the socially optimal innovation. Figure 1.2 depicts GDP and the consumption growth rate of the social planner equilibrium starting from the balanced growth path of the market economy. Section 1.6 explains the solution method in detail. Since this is a two sector economy, GDP of the social planner is calculated as if the relative price of the two sectors follows the market economy pricing. The social planner allocates more labor to research and consumption decreases immediately. As the technological progress rate increases, so does the consumption growth rate. However, it takes years for the economy to have a higher consumption growth rate than the market economy balanced growth path. After three years, the consumption growth rate surpasses 2 percent and eventually reaches the long-run rate of 3.3 percent. The GDP growth rate, on the other hand, increases initially and keeps increasing to its long-run value of 3.3 percent. Initially, the increase in the growth rate of investment leads to a higher GDP growth rate. There are two countering forces that affect the investment growth rate. Discounted capital stock goes down under the social planner, which leads to a reduction in investment. However, because of an increase in the growth rate of the quality of investment goods, investment growth rate 
goes up. The second force dominates and we observe an increase in the growth rate of investment and hence GDP. Later on, as consumption and investment growth keeps increasing, the GDP growth rate converges to 3.3 percent. The transition from the market economy balanced growth path to the social planner equilibrium generates almost 15 percent welfare gain, measured in consumption equivalent terms.

Figure 1.2: GDP and Consumption Growth Rates, Social Planner

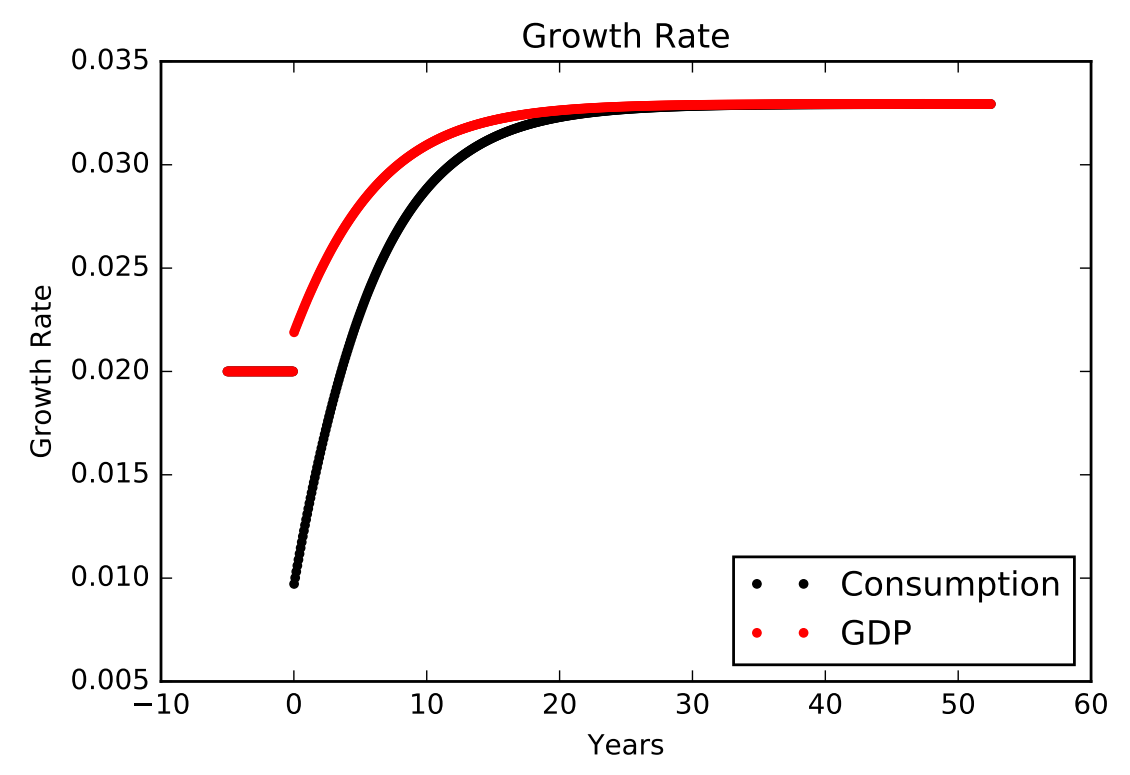

\subsection{Innovation Subsidies}

There is under-investment in innovation in both sectors as established in the previous section. Building on this result, I analyze the role of $R \& D$ subsidies in bringing the innovation rates to socially optimal levels and increasing welfare. I show that longrun welfare of the society can be increased substantially by providing R\&D subsidies to incumbent and entering firms in each sector. Considering only time-invariant 
subsidies, welfare of the society can be increased by as much as 15 percent over the long-run.

In the previous section, various distortions of the economy are explained. My focus in this section is how the government can increase welfare by subsidizing innovation in both sectors, and at what rates the innovative activities in each sector should be subsidized. To answer these questions, I compare the welfare gains of various subsidy systems, which consist of the subsidy to capital investment, entry subsidy rates in each sector, and the incumbent firm R\&D subsidy rates in each sector. The subsidy system is financed by lump-sum taxation of households. In all of the subsidy systems that I compare, the capital investment is subsidized with $1-1 / \lambda_{x}$. This amount of subsidy offsets the distortion created by the monopoly pricing of investment good producers on the capital Euler equation. Also, in all of the subsidy systems, the entry subsidy rate is adjusted relative to the incumbent firm $R \& D$ subsidy rate to make innovative resource allocation within sectors across entering and incumbent firms to be optimal. Therefore, welfare comparisons of subsidy systems reflect welfare changes resulting from total innovation in that sector.

Starting from the balanced growth path of the benchmark economy (described in the calibration section), I alter the subsidy rates (unexpected to agents in the economy) for all the subsequent times and keep them constant. Then I calculate the transition to new balanced growth path under the new subsidy system. Afterwards, I calculate the welfare gain/loss of the subsidized economy relative to the benchmark economy. The algorithm I used to calculate the welfare impacts of the subsidy systems is described as follows.

1. Discount the variables that grow at the balanced growth path with the technol- 
ogy indices that leads to growth.

2. Solve for the steady states of the benchmark economy and subsidized economy.

3. Using the reverse shooting algorithm described by Judd (1998), solve the transition of the economy from the steady state of the benchmark economy to the steady state of the subsidized economy.

4. Starting from the steady state of the benchmark economy and by normalizing the technology indices at this steady state equal to one, simulate the economy forward and generate the consumption sequence (non-discounted). Attain two consumption sequences that will be used to compute welfare gain: 1) the consumption sequence of the benchmark economy, 2) the consumption sequence of the subsidized economy.

5. Calculate the sum of discounted utility of these two consumption sequences. Equation 1.25 is the closed form solution of the sum of the discounted utility of the benchmark economy which is at the balanced growth path, where $C_{0}$ is the consumption amount at the time of subsidy change and $g_{C}$ is the consumption growth rate. The sum of discounted utility of the subsidized system is calculated using numerical integration over the utility values of consumption sequence,

$$
W\left(C_{0}, g_{C}\right)=\frac{1}{\rho}\left(\ln C_{0}+\frac{g_{C}}{\rho}\right)
$$

6. Calculate the consumption equivalent welfare change described in Equation (1.26). The welfare gain/loss is equal to $\xi$ : the rate of increase in consumption in the benchmark economy that will make the representative household indifferent 
with moving to the subsidized economy,

$$
W\left(\xi C_{0}, g_{C}\right)=\int_{0}^{\infty} \exp (-\rho t) \ln \left(C_{t}^{s}\right) d t
$$

where $C_{t}^{s}$ is consumption at time $t$ in the subsidized economy.

I calculate the welfare gain of the subsidy systems in this set: $\left\{\left(1-1 / \lambda_{d}, s_{c}, s_{x},\left(s_{c}-\right.\right.\right.$ $\left.\left.\gamma) /(1-\gamma),\left(s_{x}-\gamma\right) /(1-\gamma)\right): s_{c}=0, .02, \ldots, .9, \quad s_{x}=0, .02, \ldots, .9\right\}$. By considering subsidies from 0 percent to 90 percent, I cover all the relevant subsidy rates. The welfare gains of the subsidies in this set are depicted in Figure 1.3 as a contour map. The total amount of $R \& D$ expenditures these subsidies induce are shown in Appendix A.3

Figure 1.3: Welfare Gain

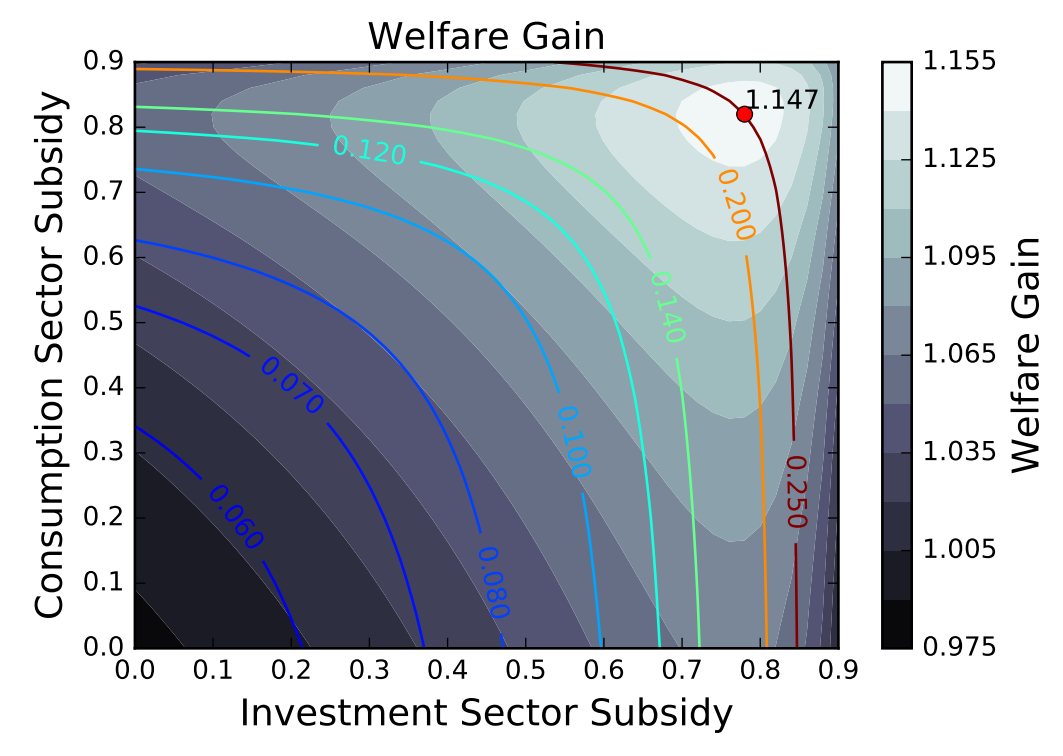

Notes: Contour map of welfare gains of R\&D subsidies. Capital investment is subsidized as well. The curves on top of contour shades show the cost of subsidies at the balanced growth path as a share of GDP at the balanced growth path. 
There are several results worth highlighting. First, holding subsidy of a sector constant as the subsidy of the other sector increases, so does the welfare gain until a certain point. Afterwards more subsidy results in a reduction in welfare gain. The same result holds when subsidies to both sectors increase simultaneously. Remembering the distortions identified in Section 1.5.2, the competitive equilibrium innovation rate can be above or below the social planner innovation rate. In this economy, it is below. Therefore, raising innovation rate to socially optimal levels leads to higher welfare. When the innovation rates surpass the optimal levels, welfare gains start decreasing. Maximum welfare gain is attained by subsidizing consumption sector R\&D by 82 percent and investment sector by 78 percent. However, this result suggests that the level of under-investment in innovation is quite high for both sectors. Second, iso-welfare curves are tilted towards investment sector $\mathrm{R} \& \mathrm{D}$ subsidy. A given rate of subsidy generates higher welfare gain when it is applied to only investment sector than when it is applied only to the consumption sector.

There are two main reasons that correcting for the distortions requires approximately 80 percent R\&D subsidy to each sector. First, as explained in the Section 1.5.3, there are large distortions in the economy. The amount of resources allocated to $R \& D$ under the social planner is more than the amount of innovative resources in the market economy. This high level of increase in resource allocation to innovation under the social planner is common in the models based on Klette and Kortum. When the general model of Atkeson and Burstein (2015) is calibrated to resemble Klette and Kortum closely, the social planner increases resource allocation to innovation three times over (eleven times over with another calibration). Lentz and Mortensen (2015) also show that social planner increases innovative resources threefold. Similarly, Segerstrom (2007) find that innovation should be heavily subsidized. 
Second, subsidizing R\&D also promotes a higher entry rate by increasing the value of firms. The higher entry rate corresponds to a higher probability for an incumbent firm to shrink by one good. In other words, inter-temporal spillover effect increases which decreases incumbent firms incentive to innovate. To compensate for the higher inter-temporal spillover, firm R\&D needs to be subsidized even more.

How does this economy achieve the maximum welfare gain? Analyzing the trajectory of consumption helps us to answer this question. Figure 1.4 shows the trajectories of consumption in the benchmark economy, when only capital investment is subsidized, an 82 percent consumption sector R\&D subsidy is added on top of the capital investment subsidy, and a 78 percent investment sector R\&D subsidy is added on top of all the other subsidies. For better comparison of consumption paths after the subsidy to the benchmark economy, I discounted each consumption path in the figure with the benchmark economy consumption. Allocating more research labor to innovation results in reduction in consumption goods production in earlier periods but a higher long-run consumption growth rate. Consumption in the consumption sector subsidized economy rebounds more quickly. However, consumption in the investment sector subsidized economy surpasses the consumption subsidized economy in later years. The reason why consumption grows more slowly in earlier periods with the investment sector subsidy lies in the response of capital to subsidies. Subsidizing investment sector R\&D leads to higher innovation rates in this sector. This leads to a lower growth rate of the price of investment goods (higher in absolute terms) and higher user cost of capital. Therefore, capital accumulates slowly. Hence, in earlier years consumption grows at a lower rate when investment sector is subsidized. Later on, after the economy reaches the balanced growth path, the higher innovative step of investment sector generates a higher consumption growth rate. Therefore, consump- 
tion in this economy catches and surpasses the benchmark and consumption sector subsidized economy.

Figure 1.4: Sequence of Consumption with Different Subsidies

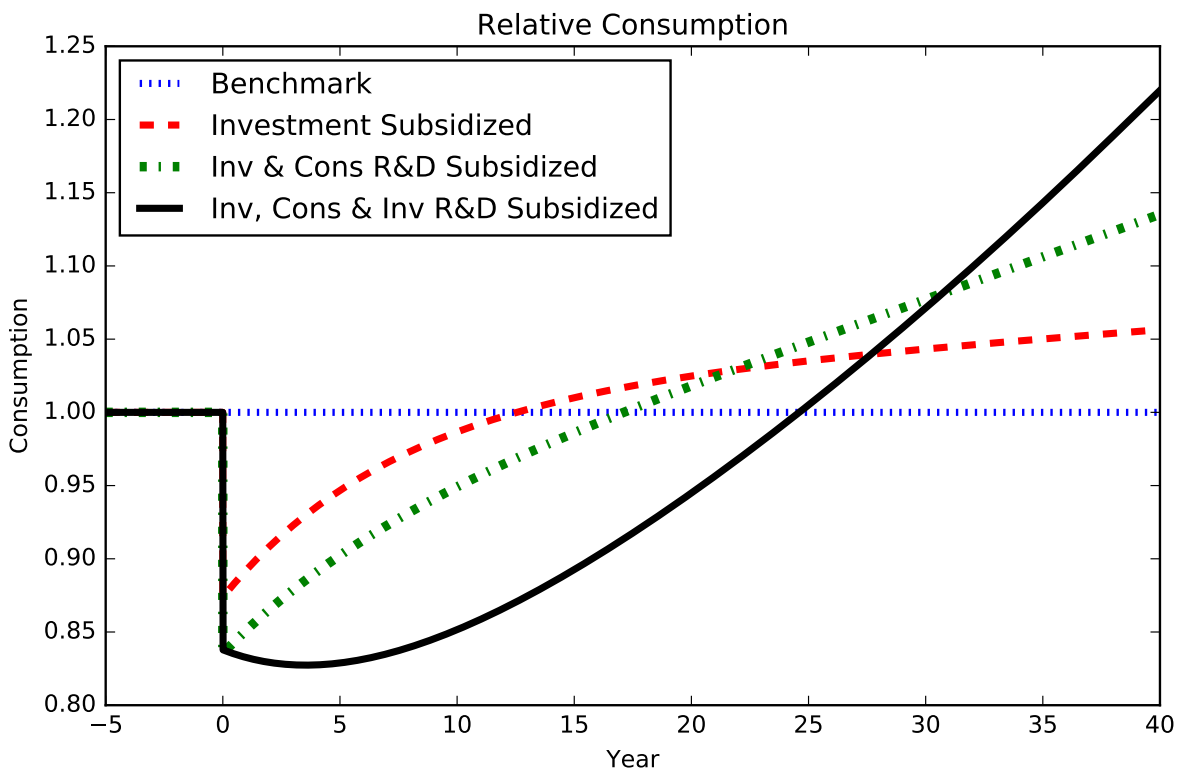

Notes: Consumption paths are relative to benchmark economy consumption level. Investment Subsidized: Benchmark with investment subsidy $\left(s_{i n}=1-1 / \lambda_{x}\right)$ added, Inv and Cons R\&D Subsidized: Investment Subsidized with Consumption R\&D subsidy of $78 \%$, Inv, Cons \& Inv R\&D subsidized: The subsidy system that maximizes the welfare gain

\subsubsection{Welfare Gain with Limited Transfer Budget}

The amount of tax collection required to subsidize the economy to reach peak welfare gain is more than 25 percent of GDP. This amount is unreasonable because of two issues that are not modeled in this paper: distortionary effects of taxation and the political economy of taxation. Therefore, a related question is how the fiscal authority should allocate subsidies across sectors if its transfer budget is limited by some factors outside of the model. In this regard, I added iso-cost curves (total subsidy as a share 
of GDP on the balanced growth path) to Figure 1.3. Comparison of intersection of iso-cost curves with the graph axises reveal that it is more costly to subsidize the investment sector. This is mainly a result of higher R\&D cost function parameters in the investment sector. Therefore, by allocating a higher subsidy rate to the consumption sector, a fiscal authority can increase the innovation rate in the consumption sector without decreasing innovation in investment sector as much. Comparison of this result with the above one introduces an interesting trade-off. On the one hand, a given rate of investment sector subsidy leads to higher welfare gain than an equal rate of consumption sector subsidy. On the other hand, a given rate of investment sector subsidy costs more than an equal rate of consumption sector subsidy. This trade-off determines the optimal allocation of limited transfer budget. In this economy, the cost advantage of the consumption sector dominates.

Figure 1.5: Optimal R\&D Subsidy

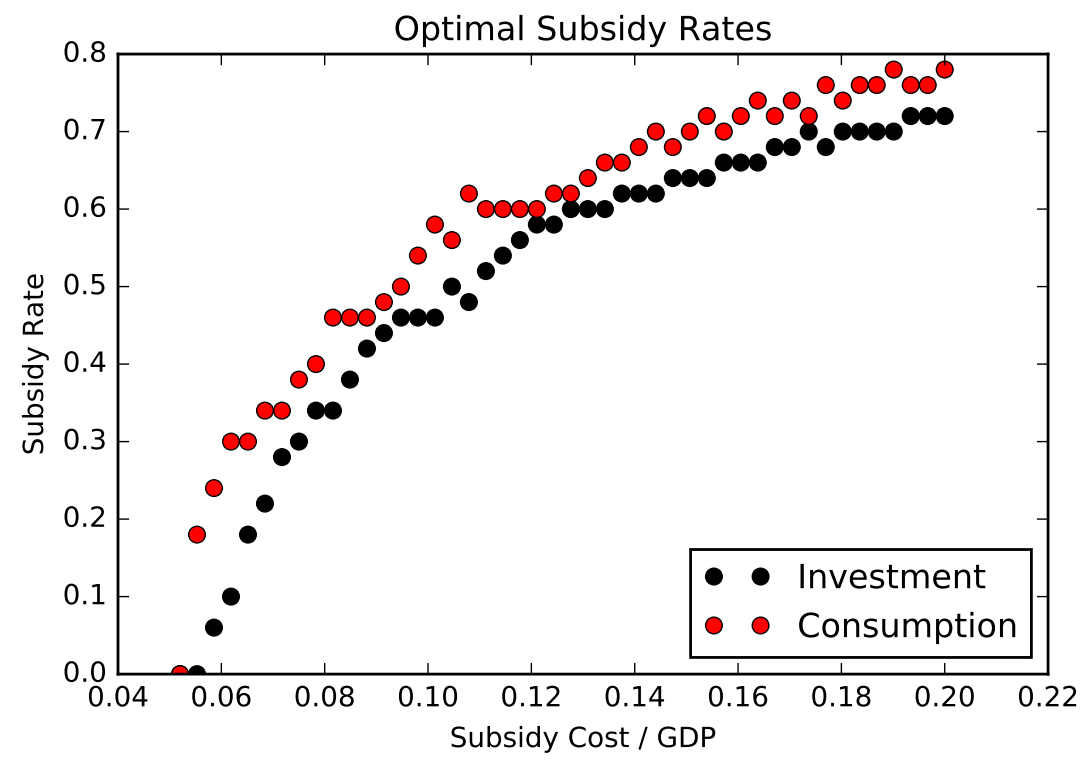

Notes: Optimal R\&D subsidies to sectors under limited transfer budget. 
Figure 1.6: Welfare Gain

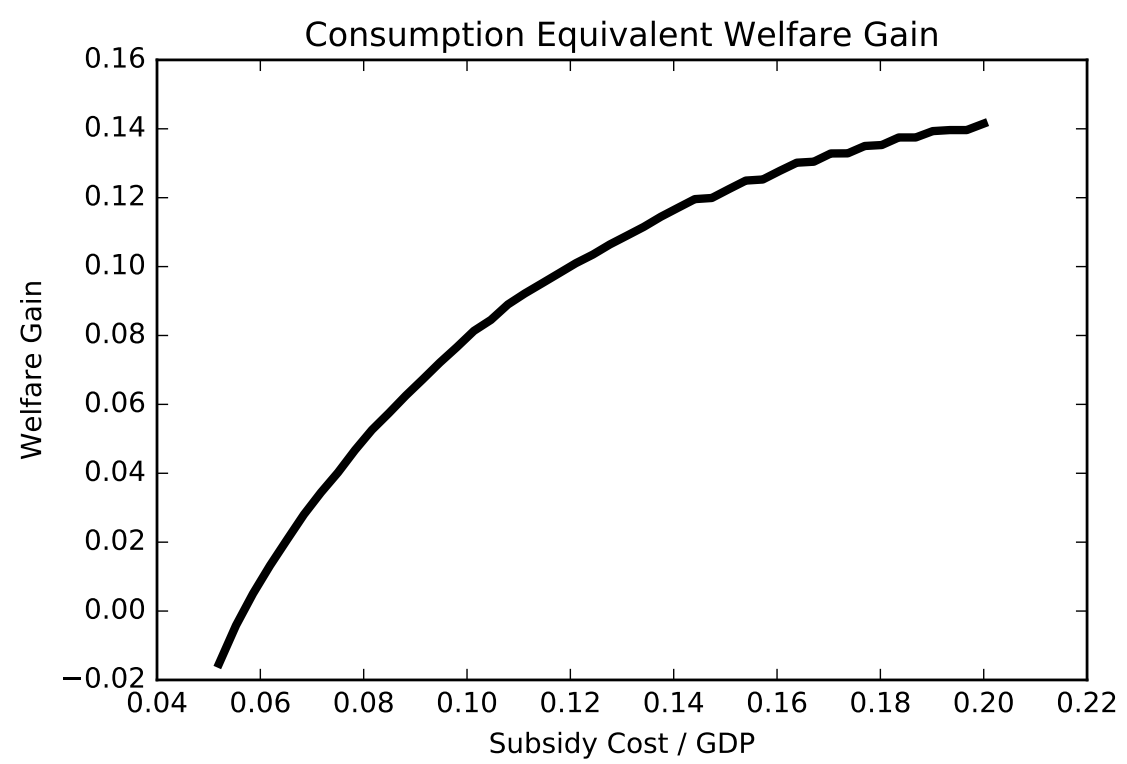

Notes: Welfare gain that can be achieved under limited transfer budget.

Figure 1.5 shows optimal government R\&D subsidy rate to sectors for different R\&D subsidy cost over GDP ratios at the balanced growth path. It is always optimal to subsidize consumption sector at a higher rate than the investment sector. For example, if the tax authority has a transfer budget of 6.5 percent of GDP (including the capital investment subsidy), it is optimal to subsidize the consumption sector by 30 percent and the investment sector by 18 percent. Figure 1.6 shows welfare gain of optimal R\&D subsidies under limited transfer budget. As the total amount of government budget allocated to R\&D subsidies increases, the welfare gain in consumption equivalent terms increase at a decreasing rate.

There is one caveat, however. In my model, there is perfect separation of consumption and investment goods. In reality, a product can be both consumed by households and invested as capital, computers for example. Because of this, an inno- 
vation in investment goods has both a direct and indirect effect on the consumption growth rate. Therefore, the contribution of the investment sector to growth will be higher than before, and vice versa for the consumption sector. The perfect separation of use of goods, in this case, reduces the welfare gain of an investment sector subsidy. Hence, we can informally argue that the investment sector should be subsidized more than as suggested above.

\subsection{Conclusion}

I analyze heterogeneity of innovative activity across sectors in a quantitative environment where firm level innovation is the main driver of the long-run macroeconomic growth. I ask how a government that wants to increase welfare of the society through R\&D subsidies should target different sectors on the economy. To answer this and related questions, I develop a quality ladder type of model based on the framework of Klette and Kortum (2004) that features two sectors: consumption goods producers and investment goods producers. These sectors differ mainly in their output's use, R\&D cost functions, and quality ladder steps sizes. An industry is classified as a consumption goods industry if household consumption of the industry's output is bigger than investment and inventory allocation made from its output. It is classified as an investment goods industry if vice versa. I calibrate my model using its firm dynamics implications and US data on job creation and destruction. An interesting

result of calibration is investment sector firms are more innovative, have a higher quality ladder step, but have a higher cost of innovation.

A sector's contribution to macroeconomic growth and welfare of the society depends on the sector's position in the supply chain of the economy, its innovation rate, 
and the quality increase (or cost reduction) of the goods after a successful innovation in the sector. Consumption sector innovation affects consumption growth directly, whereas investment sector innovation affects consumption growth indirectly through its effect on the capital stock of the economy. Also, the consumption sector generates more innovation than the investment sector. In this sense, the consumption sector contributes more to growth. However, the investment sector is more innovative. Once it innovates, it increases the quality of existing goods more than the consumption sector. The number of innovations, say on central processing units (CPUs), are lower than the number of innovations, say on restaurants. However, once a better CPU is developed, its quality increase is higher than the quality increase of better restaurant food. This last effect, higher innovativeness of investment sector dominates and this sector contributes more to long-run macroeconomic growth, more than 60 percent.

The Schumpeterian innovation process described in the model leads to various distortions in the economy and innovation rates in both sectors are lower than socially desirable levels. Therefore, government can increase the welfare of the society in the long run by subsidizing R\&D. This welfare gain, in consumption equivalent terms, can reach up to 15 percent. A given rate of $R \& D$ subsidy to the investment sector generates more welfare gain than an equal amount of R\&D subsidy to the consumption sector.

A more realistic policy question is how the government should allocate a limited transfer budget. Though the investment sector has higher innovativeness, innovation is costly in this sector. By decreasing the subsidy rate of the investment sector and allocating higher rates to the consumption sector can compensate for the lower innovativeness of consumption sector. In optimality, a subsidy system tilted toward the consumption sector generates more welfare gain than a uniform subsidy system 
with the same cost.

Many of the results rely on quality ladder steps, which are identified by four statistics: the consumption growth rate, the growth rate of the relative price of investment goods, and the innovation rates in each industry. Any mismeasurement of these statistics would lead to biased results. For example, if the growth rate of relative price of investment goods was affected by factors other than the quality increase, the results would not be accurate. Similarly, in the model, the only source of quality improvement is dedicated $R \& D$ activity. In this sense, innovation in my model is regarded in the broadest sense: any activity that leads to quality improvement is innovation. Therefore, this strong assumption also contaminates results.

Lastly, in the model, there is a perfect separation of consumption and investment goods. Not in reality. A computer, for example, is both a consumption and investment good. Therefore technological progress in investment goods would have both direct and indirect affects on consumption goods. This would make innovation in the investment sector even more important. 


\section{Appendix A}

\section{Appendix to Chapter 1}

\section{A.1 Industry Classification}

- Consumption-type:

- Retail trade, except for motor vehicles and motorcycles; repair of household goods

- Hotels and restaurants

- Finance, insurance, real estate and business services

- Community, social, and personal services

- Investment-type:

- Mining and quarrying

- Manufacturing

- Electricity, gas, and water supply

- Construction 
- Wholesale trade and commission trade, except for motor vehicles and motorcycles

- Transport, storage and communication

\section{A.2 Solution of the Model}

The representative household maximization problem is described in Section 1.2.1. Consumption is a quality adjusted aggregation of differentiated consumption goods described in Equation (1.1). Since, I solve for a symmetric equilibrium and limit pricing is assumed, highest quality versions of each differentiated consumption product gets the same positive demand, and the lower quality versions have a demand of zero. This demand function is described in Equation (1.2). Then we simplify equation 1.1 into

$$
C=\exp \left(\int_{0}^{1} \ln (q(\omega) c(\omega)) d \omega\right)
$$

where $q(\omega)$ is the highest quality level of product $\omega$, and $c(\omega)$ is the consumption of product $\omega$ with highest quality. Also, using the fact that the production function of differentiated goods in a sector is identical, and symmetric demand, the labor hired and capital rented across differentiated goods is the same, the production for each differentiated unit becomes $c(\omega)=k_{c}^{\alpha} l_{c}^{1-\alpha}$, and $k_{c}$ and $l_{c}$ do not depend on the product. Therefore, the aggregate consumption function turns into

$$
\begin{aligned}
C & =\exp \left(\int_{0}^{1} \ln \left(q(\omega) k_{c}^{\alpha} l_{c}^{1-\alpha}\right) d \omega\right) \\
C & =k_{c}^{\alpha} l_{c}^{1-\alpha} \exp \left(\int_{0}^{1} \ln (q(\omega)) d \omega\right) \\
C & =k_{c}^{\alpha} l_{c}^{1-\alpha} Q_{c}
\end{aligned}
$$


where $Q_{c}=\exp \left(\int_{0}^{1} \ln (q(\omega)) d \omega\right)$ is the average quality in the consumption sector. Equation A.4 will be used to determine the growth rate of consumption on the balanced growth path. Average price of the industry adjusted for the quality, on the other hand, is equal to

$$
\begin{aligned}
P_{c} & =\exp \left(\int_{0}^{1} \ln \frac{p(\omega)}{q(\omega)} d \omega\right) \\
& =\exp \left(\int_{0}^{1} \ln \frac{\frac{r^{\alpha} w^{1-\alpha}}{\alpha}}{q(\omega)} d \omega\right) \\
& =\frac{r^{\alpha} w^{1-\alpha}}{\alpha} \frac{1}{Q_{C}}
\end{aligned}
$$

Again, this is a result of identical innovative steps and identical production functions. I normalize the price of the consumption good to 1 :

$$
1 \equiv P_{c}=\lambda_{c} \frac{r^{\alpha} w^{1-\alpha}}{\alpha Q_{c}}
$$

Similarly, investment is a quality adjusted aggregation of differentiated investment goods. Using the same arguments as above, the demand function of differentiated investment goods can be inserted into the investment aggregator and combined with the identical production functions of differentiated investment goods, aggregate investment is written as

$$
X=k_{x}^{\alpha} l_{x}^{1-\alpha} Q_{x}
$$

where $Q_{x}=\exp \left(\int_{0}^{1} \ln (q(\omega)) d \omega\right)$ is the average quality in the investment sector. Quality adjusted average price of investment good is also equal price of each differ- 
entiated good:

$$
P_{x}=\lambda_{x} \frac{r^{\alpha} w^{1-\alpha}}{A Q_{x}} .
$$

The two other first order conditions of the household problem, consumption Euler equation and no arbitrage condition, and laws of motion of capital and asset holdings close the consumer part of the model:

$$
\begin{aligned}
& \frac{\dot{C}}{C}+\frac{\dot{P}_{c}}{P_{c}}=R-\rho \\
& r=\left(R+\delta-g_{P_{x}}\right)\left(1-s_{i n}\right) P_{x} \\
& \dot{A}=R A+w L+r K-P_{c} C-\left(1-s_{i n}\right) P_{x} X \\
& \dot{K}=X-\delta K
\end{aligned}
$$

Turning to the firm side, cost minimization problems of consumption and investment firms lead to

$$
\begin{aligned}
& r k_{c}=w l_{c}\left(\frac{\alpha}{1-\alpha}\right), \\
& r k_{x}=w l_{x}\left(\frac{\alpha}{1-\alpha}\right) .
\end{aligned}
$$

And innovation decisions of firms in both sectors generates the following conditions

$$
\begin{aligned}
& \chi_{j} \psi_{j} z_{j}^{\gamma /(1-\gamma)}=\frac{1}{1-\gamma} \chi_{j} b_{j}^{\gamma /(1-\gamma)}, \quad j=c, x, \\
& \left(R+\tau_{c}-b_{c}\right) w \chi_{c} \psi_{c} z_{c}^{\gamma /(1-\gamma)}=\pi_{c}-w \chi_{c} b_{c}^{1 /(1-\gamma)}+\frac{\partial V(1, Z)}{\partial Z} \dot{Z}, \\
& \left(R+\tau_{x}-b_{x}\right) w \chi_{x} \psi_{x} z_{x}^{\gamma /(1-\gamma)}=\pi_{x}-w \chi_{x} b_{x}^{1 /(1-\gamma)}+\frac{\partial V(1, I)}{\partial I} \dot{I},
\end{aligned}
$$


Adding the market clearing condition for labor closes the model:

$$
L=l_{c}+l_{x}+\sum_{j=c, x} \chi_{j} \psi_{j} z_{j}^{1 /(1-\gamma)}+\sum_{j=c, x} \chi_{j} b_{j}^{1 /(1-\gamma)}
$$

\section{A.2.1 Balanced Growth Path}

To find the growth rates of the variables on the balanced growth path, suppose there exists such a path and then verify it. Let $g_{a} \equiv \frac{\dot{a}}{a}$ denote the growth rate of any variable $a$ on the balanced growth path. Let $Y$ denote the GDP of the economy, $Y=C+P_{x} X$. Then the growth rate of consumption is equal to growth rate of investment expenditures, $g_{C}=g_{I}=g_{P_{x}}+g_{X}$. Using the income approach to GDP, $Y=r K+w L+R A-\dot{A}$, the growth rate of consumption is equal to growth rate of the wage rate, $g_{C}=g_{w}=g_{r}+g_{K}$. Since the price of consumption is normalized to 1 , then Equation A.8 implies that $g_{Q_{c}}=\alpha g_{r}+(1-\alpha) g_{w}$. Using the investment price formula, Equation (A.10), $g_{P_{x}}+g_{Q_{x}}=\alpha g_{r}+(1-\alpha) g_{w}$. But, in order for the no arbitrage

condition to hold, Equation A.12), the growth rate of rental rate of capital should be equal to the growth rate of the relative price of investment goods, $g_{r}=g_{P_{x}}$. Then, putting the growth rate of consumption and investment price equations together,

$$
\begin{aligned}
& g_{Q_{c}}=\alpha g_{r}+(1-\alpha) g_{w}, \\
& g_{Q_{x}}=(\alpha-1) g_{r}+(1-\alpha) g_{w},
\end{aligned}
$$

the growth rate of the wage and rental rates of capital can be solved as $g_{w}=g_{Q_{c}}+$ $\frac{\alpha}{1-\alpha} g_{Q_{x}}$, and $g_{r}=g_{Q_{c}}-\frac{1-\alpha}{1-\alpha} g_{Q_{x}}$.

Now, by using the other equilibrium conditions, I can verify that the above growth rates are indeed the balanced growth path rates. First, the growth rate of consump- 
tion should be equal to $g_{C}=\alpha g_{K}+g_{Q_{c}}$ by Equation A.4):

$$
g_{K}+g_{Q_{c}}=g_{w}-g_{r}+g_{Q_{c}}=\frac{1}{1-\alpha} g_{Q_{x}}+g_{c}
$$

where the right hand side of the equation is equal to the growth rate of wage which is equal to growth rate of the consumption. It is straightforward to verify that the other equilibrium conditions are satisfied as well.

\section{A.2.2 Growth Rates of Average Quality Levels}

In this economy innovations occur with a Poisson rate of $\tau$. Hence, in a time interval of $t$, the probability of exactly $m$ innovations occur is equal to $f(m, t)=\frac{(\tau t)^{m} \exp (-\tau t)}{m !}$. Assuming the law of large numbers holds, the probability of having exactly m innovations in a time interval is equal to measure of products that had $m$ innovations in that interval Grossman and Helpman (1991) ]. Plugging this back into the average quality level equation,

$$
\begin{aligned}
Q_{t} & =\exp \left(\int_{0}^{1} \ln q(\omega) d \omega\right) \\
& =\exp \left(\sum_{m=0}^{\infty} f(m, t) \ln \lambda^{m}\right) \\
& =\exp \left(\ln \lambda \sum_{m=0}^{\infty} f(m, t) m\right) \\
& =\exp (\ln (\lambda) \tau t),
\end{aligned}
$$


where the latter step is from the expectation of the Poisson distribution. Then the growth rate of average technology in each industry is equal to

$$
\frac{\dot{Q}_{j}}{Q_{j}}=\tau_{j} \ln \lambda_{j}, \quad j=c, x .
$$

\section{A.3 R\&D Expenditure as a Share of GDP}

This section shows the total R\&D expenditures as a share of GDP at the balanced growth path.

Figure A.1: Total R\&D Expenditure as a Share of GDP

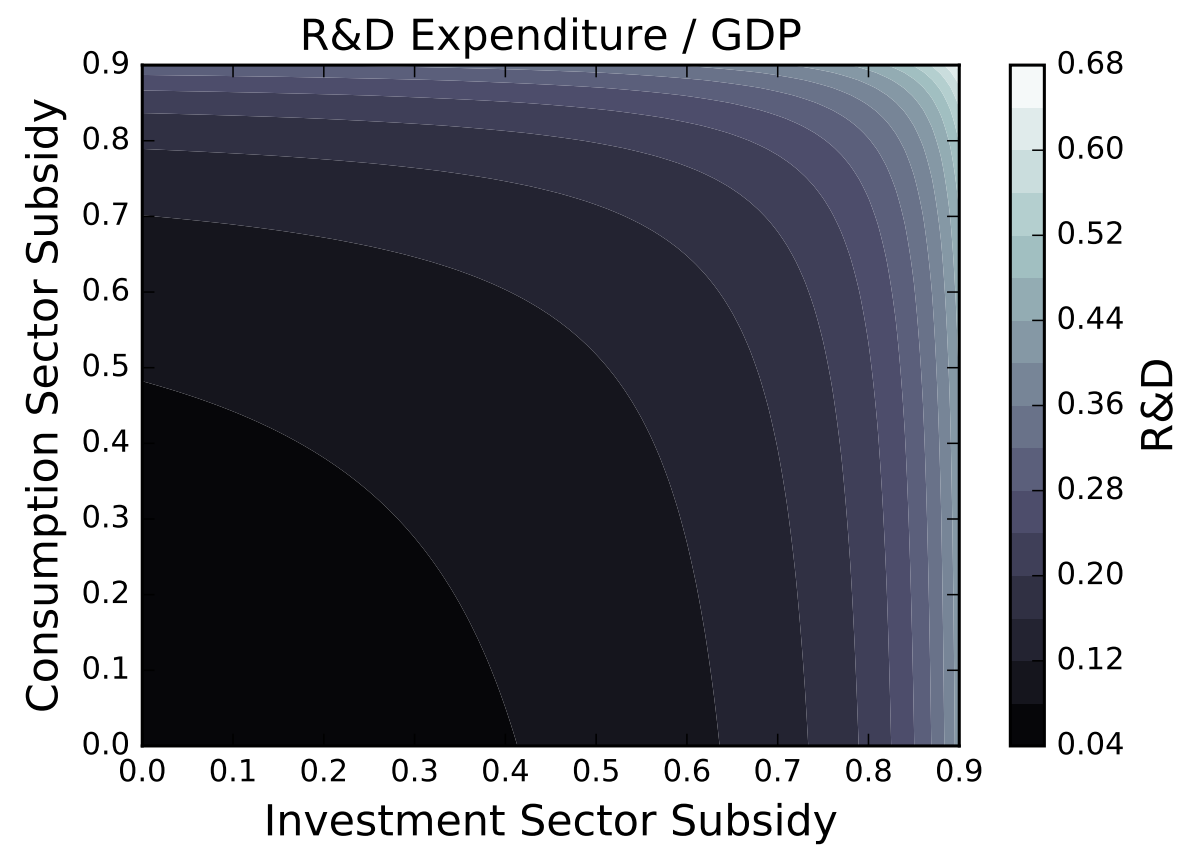

Notes: Contour map of R\&D expenditure as a share of GDP at the balanced growth path. 


\section{Chapter 2}

\section{Worker Flows over the Life Cycle Tomaz Cajner, İlhan Güner, Toshiniko Mukoyama 1}

\section{$2.1 \quad$ Introduction}

In recent years, substantial research efforts - both in terms of providing empirical evidence and constructing theoretical models - have led to findings that have transformed the way economists think about the aggregate labor market. Researchers have shown that, by looking beyond stocks and analyzing gross flows, one can obtain deeper insights into the workings of the labor market and evaluate policies more properly. In particular, much progress has been made in understanding how each of these gross flows contributes to the responses of the aggregate labor market to various aggregate shocks and policies.

Relatively less progress has been made in how various aggregate shocks and poli-

\footnotetext{
${ }^{1}$ Tomaz Cajner, Federal Reserve Board, tomaz.cajner@frb.gov. İhan Güner, University of Virginia, ig7xs@virginia.edu. Toshihiko Mukoyama, University of Virginia, tm5hs@virginia.edu. The views in this paper are those of the authors and do not necessarily represent the views or policies of the Board of Governors of the Federal Reserve System or its staff. The results are still preliminary. Comments welcome.
} 
cies affect individual labor market experiences over the life cycle. Over their lives, individuals frequently change their labor market status, moving between employment, unemployment, and out of the labor force. Additionally, they often switch employers while employed. The main goal of this paper is to contribute towards our understanding of the labor market by analyzing these worker flows over the life cycle, both empirically and theoretically.

Our research is motivated by the labor market in the aftermath of the 2008-2009 recession. One emerging consensus on both the academic and the policy front is that looking only at the unemployment rate is not sufficient to evaluate the performance of the labor market. In particular, there are three new elements that have been emphasized.

First, one has to go beyond the unemployment rate of labor force participants and look also into labor force participation. The labor force participation rate is affected by many factors, including demographics and business cycles. Second, one has to go beyond stocks and look at labor market flows. The movement of the unemployment rate is affected by the inflow into and outflow from unemployment, as well as flows into and out of employment. In general, there are substantial flows across the three labor market states (employment, unemployment, and not in labor force) and each of them has a distinct cyclical pattern. Analyzing gross flows of the workers rather than the change in stocks would provide significantly richer information about the working of the labor market. Third, there is a significant amount of worker movement of employed workers across different jobs - about $1 \%$ to $3 \%$ of employed workers change their jobs in each month. This job-to-job transition is often overlooked but this is an important part of worker reallocation. This paper incorporates all three of these factors. 
Our emphasis is on the life-cycle patterns of the labor market experiences. The paper first presents empirical evidence on the patterns of labor market flows by age, with a particular emphasis on their cyclical behavior during the Great Recession. In order to isolate the life cycle effects on worker flows from changes in educational composition by age - it is well known that worker flows differ systematically by education - we focus on the group of male college graduates. We find that young people exhibit particularly high transition rates between all three labor market states as well as high job-to-job transition rates. Most labor market transition rates are declining over the life cycle, with transition rates out of the labor force increasing late in life when individuals approach retirement. In terms of cyclicality, the data indicate high variation of transition rates between employment and unemployment over the business cycle for individuals of all ages. It is also shown that young people experience the largest decline in job-to-job transition rates during economic downturns.

We then proceed by constructing a theoretical life cycle model to understand these patterns in the data. Our model extends Krusell et al. (2016) to a life-cycle setting. The model features consumers who optimize in consumption-saving decisions, labor-market participation decisions, and face labor-market frictions. The model is a parsimonious partial equilibrium model; however, Krusell et al. (2016) have shown that the infinite-horizon version of the model fits the average and business-cycle patterns of the labor market flows very well. We quantitatively evaluate whether the model's success translates into the life-cycle context.

After parameterizing this parsimonious model, we compare the steady-state performance of the model to the data. We find that once we assume that the job-offer probabilities are declining with age, the model can replicate many salient patterns of the gross worker flows over the life cycle. However, there are several flows whose 
model patterns are at odds with data. We offer explanations for these discrepancies.

We compare the steady states of our model, with different levels of labor-market frictions, to the data during and after the Great Recession. The model performs well in qualitatively replicating the patterns we observe in the data. We also observe that there are some notable quantitative failures of the model. This exercise provides a useful starting point for future investigations.

This chapter is organized as follows. Section 2.2 provides a brief literature review. Section (2.3) describes what we observe in the data. Section (2.4) sets up our model, which is calibrated in Section (2.5). Section (2.6) provides the model results. Section 2.7 concludes.

\section{$2.2 \quad$ Related Literature}

A number of recent papers analyze the labor market over the business cycle from the viewpoint of gross worker flows (Elsby et al., 2009, 2010; Shimer, 2012). While initially these papers mostly focused on the relative importance of inflows and outflows in the determination of unemployment in post-war business cycles, a recent contribution by Elsby et al. (2013) emphasize the importance of the labor force participation margin in analyzing the cyclicality of the labor market. Moreover, a recent paper by Choi et al. (2015) conducts an accounting exercise in the life cycle context and analyzes how each flow contributes to the life cycle dynamics of the unemployment rate and the labor force participation rate. They argue that flows that involve non-participation are important in accounting for the life cycle dynamics of unemployment and labor force participation.

Macroeconomists have long recognized that business cycle fluctuations in gen- 
eral and labor market shocks in particular might have a heterogeneous impact on different demographic groups, necessitating theoretical models that go beyond the representative-agent abstraction (Kydland, 1984). One of the first theoretical models that were intentionally geared towards explaining fluctuations in hours worked by age were overlapping-generations models by Ríos-Rull (1996) and Gomme et al. (2005). More recently, several papers extended the equilibrium unemployment model of Mortensen and Pissarides (1994) by introducing the life cycle aspects of worker flows. Chéron et al. (2013) allow for exogenous exits to retirement at some predetermined age and endogenous search effort. Esteban-Pretel and Fujimoto (2014) build a life cycle search and matching model with accumulation of general human capital and learning about match quality, which is directly linked to the worker's skill level. Moreover, Menzio et al. (2012) and Jung and Kuhn (2014) provide life cycle models with directed search where the labor market is segmented by age. However, none of the mentioned papers explicitly models the unemployment and non-participation margins separately. Similarly, none of them look at business cycles. Finally, recent microeconomic studies, such as Kahn (2010), argue that the effect of entering the labor market in recessions is long-lasting, while Mukoyama (2014) builds a job-ladder model and demonstrates that the recent decline in the job-to-job transition rate may have had a large impact on aggregate productivity in the United States.

\subsection{Empirical Observations}

In this section we first document how individuals move across different labor market states (employment, unemployment, and not in the labor force) as well as how often they make a job-to-job transition. By now it is well known that education affects 
worker flows; for example, college graduates experience much lower transitions from employment to unemployment than high school graduates, resulting in comparatively lower unemployment rates for individuals with a college degree. In order to isolate the life cycle effects on worker flows from changes in educational composition by age, we focus on a particular education group: college graduates.

\subsubsection{Data}

We use the monthly files of the Current Population Survey (CPS). CPS interviews households for four consecutive months, and interviews for another 4 consecutive months after 8 months of no interviewing. This quasi-panel structure of CPS allows us to construct gross worker flows across labor market states. We have information about gender, education level, job search activities, and employment status of individuals in the survey. In our analysis, we consider only college graduates, and calculate worker flows for males and females separately. We construct gross worker flows across labor market states by using the changes in employment status of individuals from one month to the next month. Furthermore, the survey question regarding whether the interviewee works for the same employer allows us to construct job-to-job transitions.

\subsubsection{Labor Market Stocks}

Figure 2.1 depicts the unemployment rate and the labor force participation rate for college graduates over the life cycle, separately for both genders. We plot averages from 1994 to 2013, constructed from the CPS micro data. As is well known, the unemployment rate steeply declines early in life and then becomes relatively flat, with the pattern being similar for both genders. On the other hand, the labor force par- 

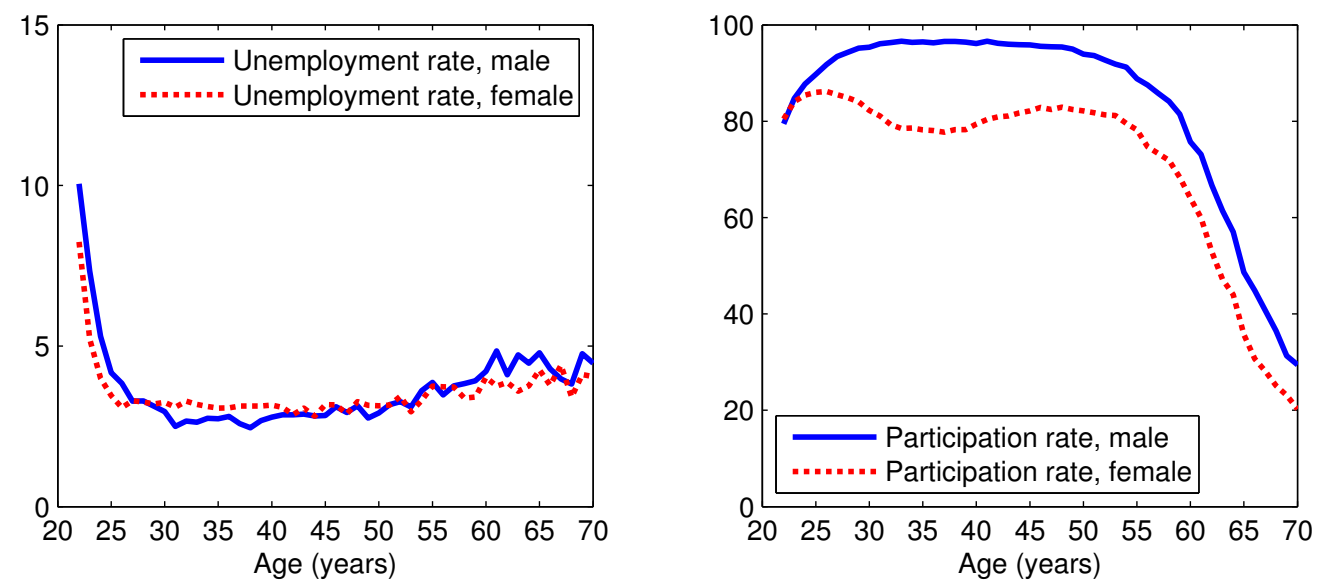

Figure 2.1: Unemployment and labor force participation of college graduates over the life cycle

ticipation rate increases early in life, remains broadly flat for prime-age (25-54 years) workers, and then begins declining. Female labor force participation is somewhat lower, with the gap being the largest during the childbearing years.

\subsubsection{Labor Market Flows}

Figure 2.2 shows the main six monthly labor market transition rates for college graduates over the life cycle, again separately for both genders. These transition rates have been constructed from monthly-matched CPS micro data from 1994 to 2013 and smoothed over age by taking 7 -year centered moving averages. The main difference between males and females can be seen in transition rates involving the nonparticipation state during the childbearing years when women are more likely to exit the labor force and stay out of the labor force. In terms of the life cycle patterns, employment exit (EU and EN) rates follow a U-shape pattern. The job-finding (UE) rate is monotonically decreasing with age, while the UN transition is relatively flat

before rising late in life. Transition rates into the labor force are generally declining 

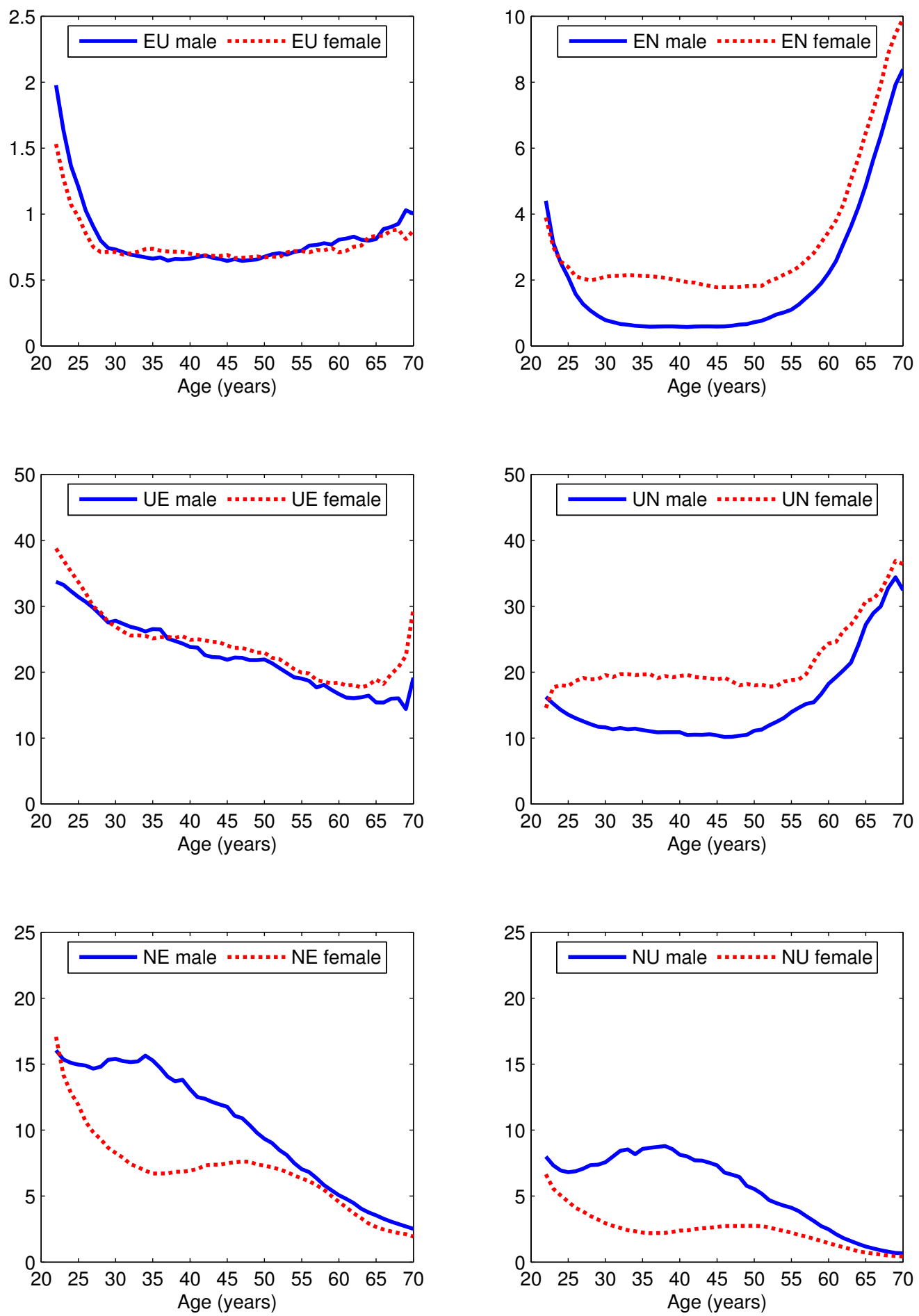

Figure 2.2: Monthly labor market flows of college graduates over the life cycle 

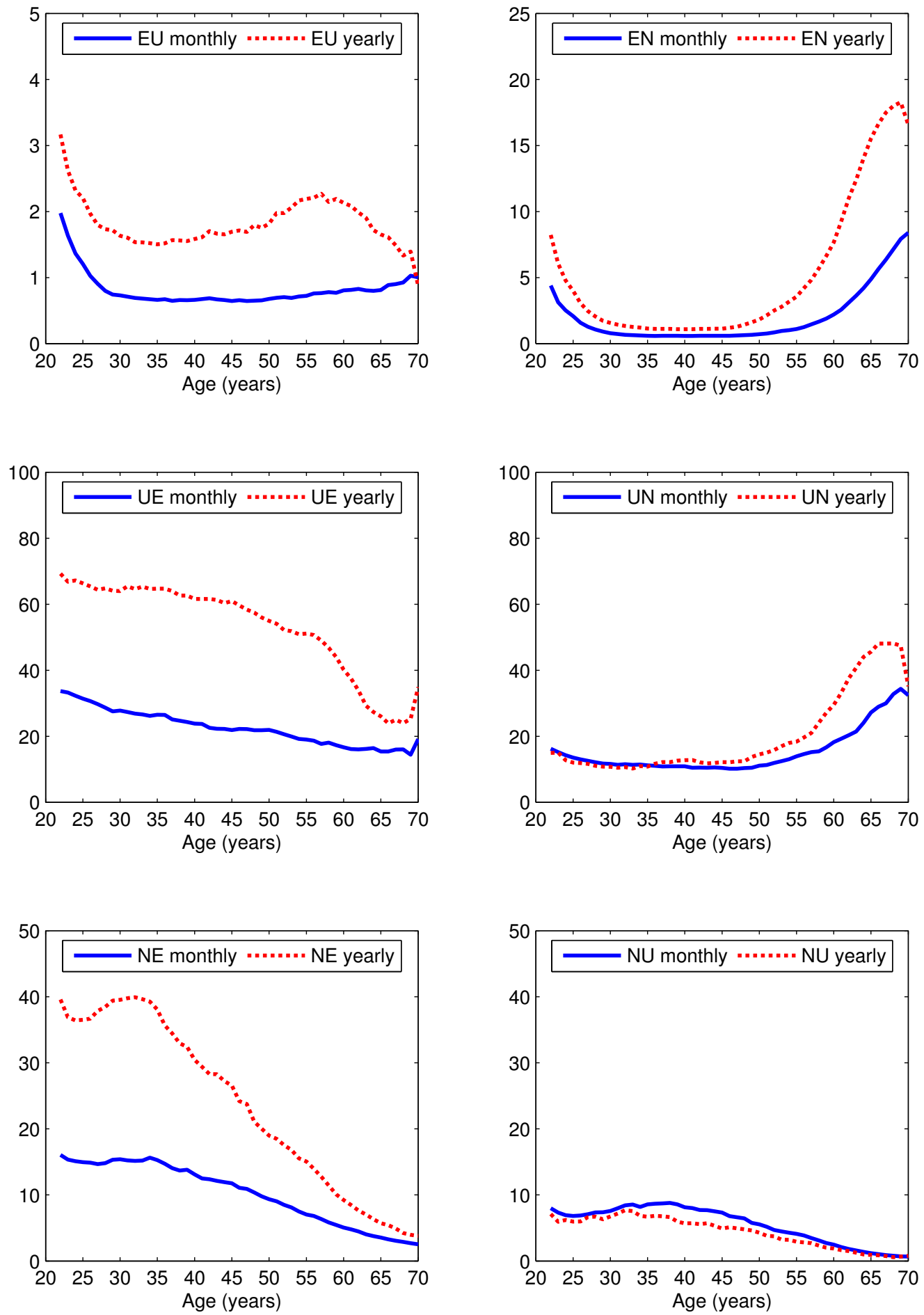

Figure 2.3: Monthly and yearly flows for male college graduates over the life cycle 
with age.

In Figure 2.3 we plot labor market flows for male college graduates that are matched monthly and yearly (the quasi-panel structure of the CPS allows for matching at both frequencies; we again smooth over age by taking 7 -year centered moving averages). Yearly labor market flows involving employment are substantially higher than monthly flows, as expected. Interestingly, labor market flows between unemployment and non-participation are of remarkably similar magnitudes for most ages. One possible interpretation is that most $\mathrm{UN}$ and $\mathrm{NU}$ transitions are made by individuals at the margin of labor market participation.

\subsubsection{Business Cycles - The Great Recession}

In order to show how the business cycle interacts with the life cycle, Figure 2.4 provides labor market flows of male college graduates by age for two time periods: the period of expansion preceding the Great Recession (2005-2007) and the period of the Great Recession and its immediate aftermath (2008-2010) $?^{2}$

There are a few noticeable features. First, the cyclicality is uniform for the most of the flows. UE, UN, NE flows are all procyclical for almost all ages, while EU and NU flows are countercyclical for almost all ages. The EN flow is an exception. While Krusell et al. (2016) show that it is procyclical overall, its cyclicality is weaker in the graph and its procyclicality is limited to prime-ages. Second, overall the flows that involve the $\mathrm{N}$ state vary less over the cycle compared to the flows between $\mathrm{E}$ and $\mathrm{U}$.

\footnotetext{
${ }^{2}$ While the NBER's Business Cycle Dating Committee determined that the Great Recession lasted from December 2007 until June 2009, the deterioration of labor market conditions - as illustrated, among other indicators, by raising unemployment and negative payroll employment growth - continued after the "official" end of the Great Recession.
} 

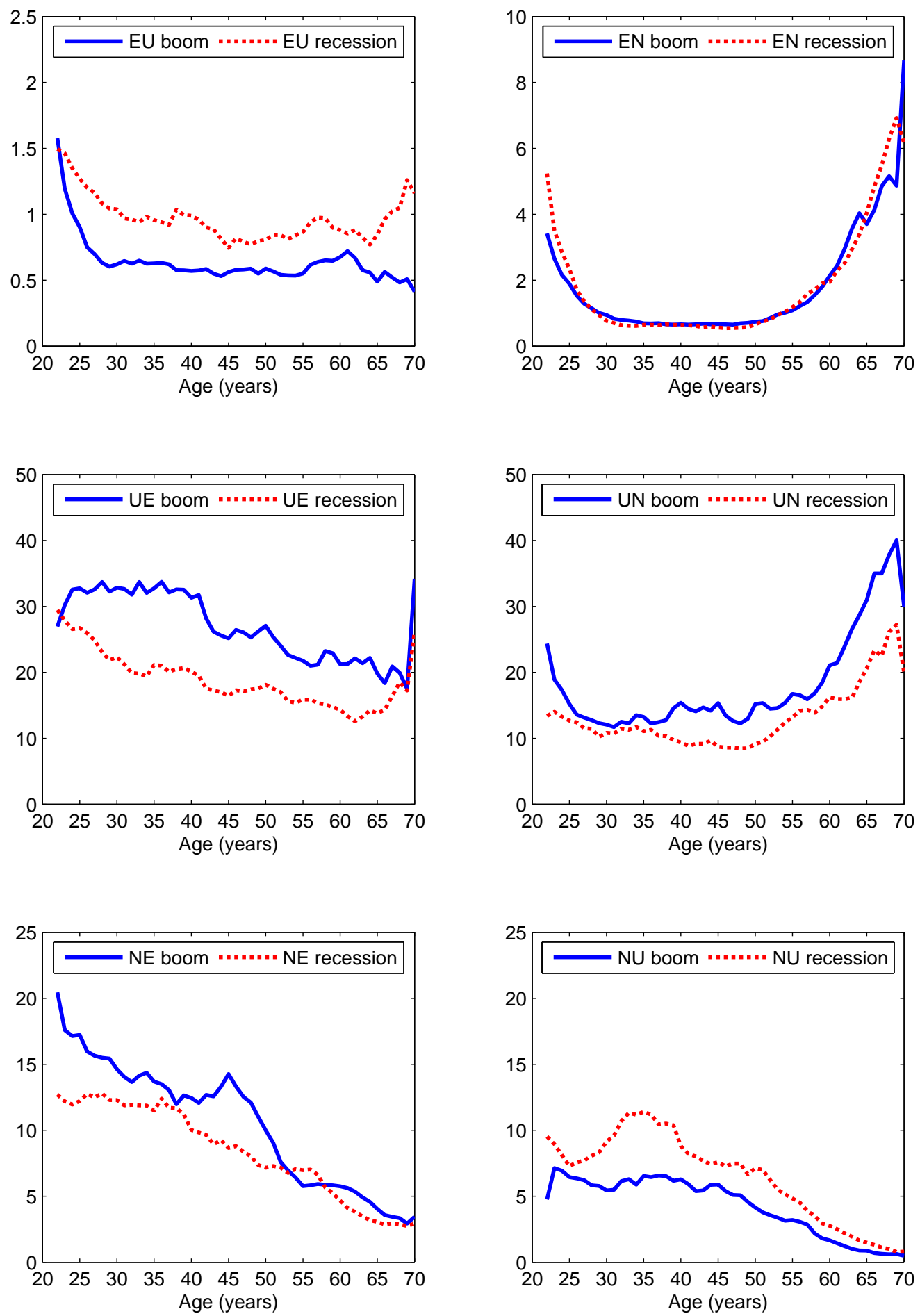

Figure 2.4: Monthly flows for male college graduates over the life cycle: boom (200507) vs. recession (2008-10) 

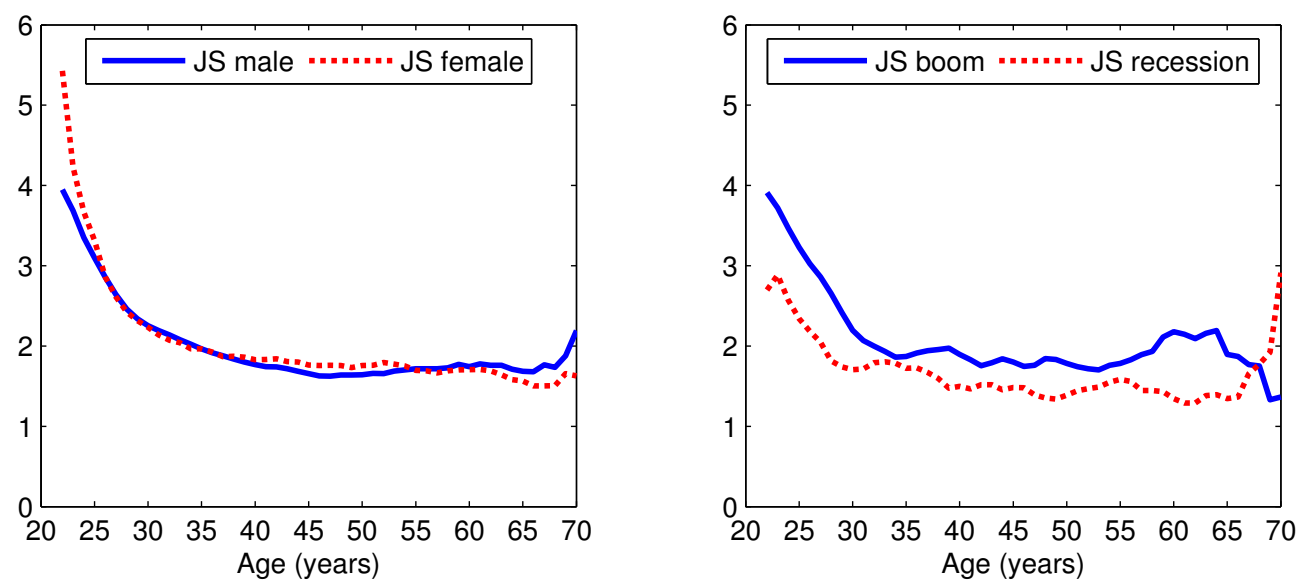

Figure 2.5: Monthly job-to-job transitions for college graduates over the life cycle (left panel) and over the business cycle (males, right panel)

\subsubsection{Job-to-Job Transitions}

The left panel of Figure 2.5 plots the monthly job-to-job transition rate. Its life cycle pattern resembles the pattern of the job-finding rate, with the main difference being a somewhat steeper decline early in life, which likely reflects job-hopping of young college graduates. Furthermore, the right panel of Figure 2.5 indicates that job-tojob transitions for male college graduates are pro-cyclical and especially so for young people. 


\subsection{Model}

This section builds a partial equilibrium search and matching model that incorporates:

(i) the life cycle, (ii) savings decision, (iii) workers' idiosyncratic productivity shocks, (iv) match quality shocks, and (v) the participation margin.

\subsubsection{Technology and Preferences}

A worker is characterized by (i) her labor market state: employed (has a job), unemployed (not employed but actively searching for a job), not in labor force (not employed and not searching for a job) ${ }^{3}$, (ii) her wealth, $a$, (iii) her idiosyncratic productivity shock, $z$, (iv) her match quality shock (if employed), $\mu$, and (v) her age, $j$. Let $s_{j}$ be the survival probability of a worker from age $j$ to $j+1$. Then each worker maximizes:

$$
\mathbf{U}_{w}=\sum_{j=1}^{J}\left(\beta^{j} \prod_{t=1}^{j} s_{t}\right) \frac{c_{j}^{1-\gamma}-1}{1-\gamma}
$$

where $c_{j}$ is the consumption at age $j \in\{1, \ldots, J\}$, and $\gamma$ is the inverse of the elasticity of inter-temporal substitution.

The idiosyncratic productivity shock, $z$, follows an AR(1) process. Each period, a worker receives a job offer with a probability that depends on her labor market status and age. $\lambda_{u, j}, \lambda_{n, j}, \lambda_{e, j}$ are job offer probabilities of unemployed, not-in-labor-force, and employed workers at age $j$. Since an unemployed worker engages in active search, she incurs a search cost of $\psi$. An employed worker with idiosyncratic shock $z$, match quality $\mu$ and age $j$ receives wage $\omega_{j}(\mu, z)=g(j) \mu z \tilde{\omega}$, where the function $g(j)$ is the deterministic age component, and $\tilde{\omega}$ is the scale parameter. As long as a specific

\footnotetext{
'The terms 'not in labor force' and 'non-participant' are used interchangeably in this text.
} 
firm-worker match is preserved, $\mu$ follows an $\mathrm{AR}(1)$ process. Not working leads to home production of $b(j)$ for unemployed and non-in-labor-force workers.

\subsubsection{Initial Match Quality Draws}

Upon being matched, the worker-firm pair draws a match quality $(\mu)$ shock. We assume that match quality shocks are drawn independently from a Pareto distribution with parameters $\left(\mu_{1}, \alpha\right)$, where $\mu_{1}$ is the lower bound of the support of the match quality distribution and $\alpha$ determines the rate with which the density of the distribution decreases (note that $M$ denotes the random variable and $\mu$ its realization):

$$
\operatorname{Pr}(M>\mu)=\left\{\begin{array}{cl}
\left(\frac{\mu_{1}}{\mu}\right)^{\alpha} & \text { for } \mu \geq \mu_{1} \\
1 & \text { for } \mu<\mu_{1}
\end{array}\right.
$$

The initial match quality for workers that obtain an outside job offer is drawn from the same distribution. For workers in existing job matches, the match quality follows an $\mathrm{AR}(1)$ process.

\subsubsection{Timing}

Timing within a period is as follows:

1. Idiosyncratic productivity shocks and match quality shocks for existing matches are realized.

2. Workers and firms match, the initial match quality shocks are drawn.

3. Nonemployed workers decide whether to accept the match. 
4. Employed workers decide whether to move or not. They commit to this decision.

5. Production and consumption.

6. Possible death, separation shock.

\subsubsection{Bellman Equations for Workers}

Let the value function of an employed worker at age $j$ be $W_{j}(\mu, z, a)$, the value function of an unemployed worker be $U_{j}(z, a)$, and the value function of a non-in-the-laborforce worker be $N_{j}(z, a)$.

The Bellman equation for the employed is:

$$
\begin{aligned}
W_{j}(\mu, z, a)=\max _{c_{j}, a^{\prime}}\left\{u\left(c_{j}\right)+\beta s_{j} E_{\mu^{\prime}, z^{\prime}}[\right. & (1-\sigma)\left(1-\lambda_{e, j}\right) T_{j+1}\left(\mu^{\prime}, z^{\prime}, a^{\prime}\right) \\
& +(1-\sigma) \lambda_{e, j} S_{j+1}\left(\mu^{\prime}, z^{\prime}, a^{\prime}\right) \\
& +\sigma\left(1-\lambda_{e, j}\right) O_{j+1}\left(z^{\prime}, a^{\prime}\right) \\
& \left.\left.+\sigma \lambda_{e, j} F_{j+1}\left(z^{\prime}, a^{\prime}\right)\right]\right\}
\end{aligned}
$$

subject to

$$
c_{j}+a^{\prime}=(1+r) a+\omega_{j}(\mu, z)
$$


where

$$
\begin{aligned}
T_{j+1}\left(\mu^{\prime}, z^{\prime}, a^{\prime}\right) & =\max \left\{W_{j+1}\left(\mu^{\prime}, z^{\prime}, a^{\prime}\right), O_{j+1}\left(z^{\prime}, a^{\prime}\right)\right\}, \\
S_{j+1}\left(\mu^{\prime}, z^{\prime}, a^{\prime}\right) & =\int_{\underline{\mu}}^{\bar{\mu}} \max \left\{T_{j+1}\left(\mu^{\prime}, z^{\prime}, a^{\prime}\right), W_{j+1}\left(\mu, z^{\prime}, a^{\prime}\right)\right\} d G(\mu), \\
O_{j+1}\left(z^{\prime}, a^{\prime}\right) & =\max \left\{U_{j+1}\left(z^{\prime}, a^{\prime}\right), N_{t+1}\left(z^{\prime}, a^{\prime}\right)\right\}, \\
F_{j+1}\left(z^{\prime}, a^{\prime}\right) & =\int_{\underline{\mu}}^{\bar{\mu}} \max \left\{W_{j+1}\left(\mu, z^{\prime}, a^{\prime}\right), O_{j+1}\left(z^{\prime}, a^{\prime}\right)\right\} d G(\mu),
\end{aligned}
$$

where $r$ is the real interest rate. Each employed worker faces four possible scenarios in the next period: (i) not receiving a separation shock $(\sigma)$ nor an outside job offer, in which case she needs to decide between continuing with employment or becoming nonemployed (Bellman equation $T$ ), (ii) not receiving a separation shock, but getting an outside job offer, in which case she additionally needs to decide whether to switch or not $(S)$, where $G(\cdot)$ is the outside wage offer distribution, (iii) getting a separation shock and no outside offer, in which case she becomes nonemployed and needs to decide whether to search or not $(O)$; (iv) getting a separation shock and an outside job offer, in which case she can move directly to another firm $(F)$.

The Bellman equation for the unemployed is:

$$
U_{j}(z, a)=\max _{a^{\prime}, c_{j}}\left\{u\left(c_{j}\right)+\beta s_{j} E_{z^{\prime}, Z^{\prime}}\left[\lambda_{u, j} F_{j+1}\left(z^{\prime}, a^{\prime}\right)+\left(1-\lambda_{u, j}\right) O_{j+1}\left(z^{\prime}, a^{\prime}\right)\right]\right\},
$$

subject to

$$
c_{j}+a^{\prime}=(1+r) a+b(j)-\psi
$$

where $b$ is the age-deterministic home production and $\psi$ is the search cost.

Those not in the labor force are not subject to the search cost, but their finding 
probability will be different (lower) as explained later on:

$$
N_{j}\left(z, a^{\prime}\right)=\max _{a^{\prime}, c_{j}}\left\{u\left(c_{j}\right)+\beta s_{j} E_{z^{\prime}, Z^{\prime}}\left[\lambda_{n, j} F_{j+1}\left(z^{\prime}, a^{\prime}\right)+\left(1-\lambda_{n, j}\right) O_{j+1}\left(z^{\prime}, a^{\prime}\right)\right]\right\} .
$$

subject to

$$
c_{j}+a^{\prime}=(1+r) a+b(j) .
$$

\subsection{Calibration}

The model frequency is monthly and the main parameters are provided in Table 2.1 $\beta$ is chosen to have a .95 annual discount factor. The elasticity of inter-temporal substitution is equal to 2 . The exogenous job separation rate is equal to .008. Job offer probabilities are parameterized as a linear function of age (in months). The probability of a younger worker getting a job offer is higher than that of an older worker. Home productivity is equal to .46 and the search cost of unemployed workers is .06, approximately $13 \%$ of home production. The idiosyncratic productivity shock has an $\mathrm{AR}(1)$ process with a coefficient equal to .97 and the standard deviation of the error is equal to .1. Similarly, the match quality shock has an AR(1) process with a coefficient of .98 and the standard deviation of error is equal to .13. Both processes are approximated using Tauchen method.

Additionally, we need to parameterize workers' survival probabilities over the life cycle. We obtain these numbers from the Social Security Administration, which calculates mortality rates $4^{4}$ The left panel of Figure 2.6 depicts the cumulative survival rate by age that is used in the model.

\footnotetext{
${ }^{4}$ Ideally, we would use mortality rates for male college graduates, but since those are not available, we use mortality rates for males by age. See: http://www.ssa.gov/OACT/STATS/table4c6.html.
} 
Table 2.1: Model's parameters

\begin{tabular}{lcc}
\hline \hline Parameter & Symbol & Value \\
\hline Maximum age (in months) & $J$ & $12 \times 79$ \\
Discount factor & $\beta$ & $0.95^{1 / 12}$ \\
Inverse of elasticity of inter-temporal substitution & $\gamma$ & 2 \\
Exogenous separation rate & $\sigma$ & 0.008 \\
Search cost & $\psi$ & 0.06 \\
Job offer probability, intercept, unemployed & $\lambda_{u}$ & 0.38 \\
Job offer probability, slope, unemployed & $m_{u}$ & -0.0004 \\
Job offer probability, intercept, non-participant & $\lambda_{n}$ & 0.31 \\
Job offer probability, slope, non-participant & $m_{n}$ & -0.0003 \\
Job offer probability, intercept, employed & $\lambda_{e}$ & 0.30 \\
Job offer probability, slope, employed & $m_{e}$ & -0.0004 \\
Wage scale & $\tilde{\omega}$ & 3.0 \\
Idiosyncratic prod., AR(1) & $\rho_{z}$ & 0.97 \\
Idiosyncratic prod., std.dev. & $\sigma_{z}$ & 0.1 \\
Match quality, AR (1) & $\rho_{\mu}$ & 0.98 \\
Match quality, std.dev. & $\sigma_{\mu}$ & 0.13 \\
Match quality, Pareto parameter & $\alpha$ & 2 \\
Home productivity & $b$ & .46 \\
\hline
\end{tabular}



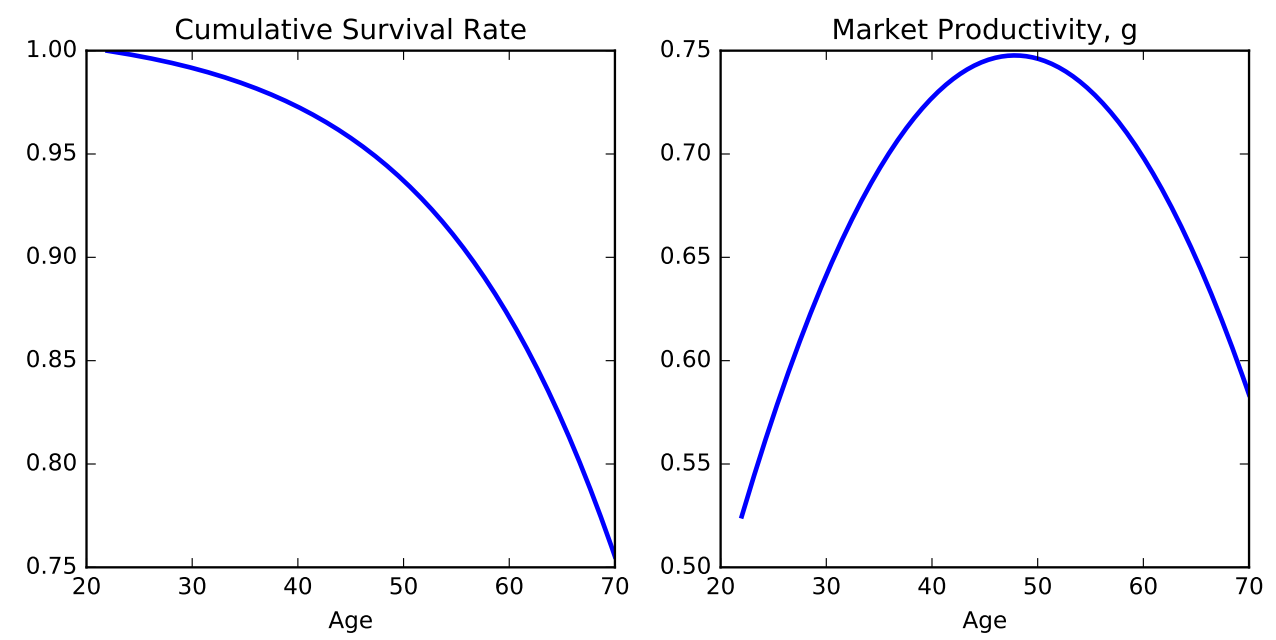

Figure 2.6: Cumulative survival rate and market productivity

Finally, we need to parameterize the worker's market productivity, $g(j)$, which is a deterministic function of age. Our target for the market productivity is the lifecycle profile of real wages for college graduates. $5^{5}$ The right panel of Figure 2.6 provides market and home productivity levels by age that are used in the model 6

\section{$2.6 \quad$ Results}

We solve for the model's equilibrium numerically. We allow agents to live up to 100 years; this, however, does not represent a binding constraint since by the age of 80 , essentially everyone in the model drops out of the labor force. Note that in contrast with much of the life-cycle literature, we do not need to exogenously impose a fixed retirement age. Instead, we parametrize the market and home productivity profiles

\footnotetext{
${ }^{5}$ We calculate the real wage for college graduates by age from the CPS microdata, with top-coding adjustment assuming log normal distribution of weekly earnings and adjusting for overtime, tips, and commissions. Wages are deflated by the Consumer Price Index Research Series Using Current Methods (CPI-U-RS). For further details, see Schmitt (2003).

${ }^{6}$ We use the second order polynomial in order to parametrize market productivity.
} 

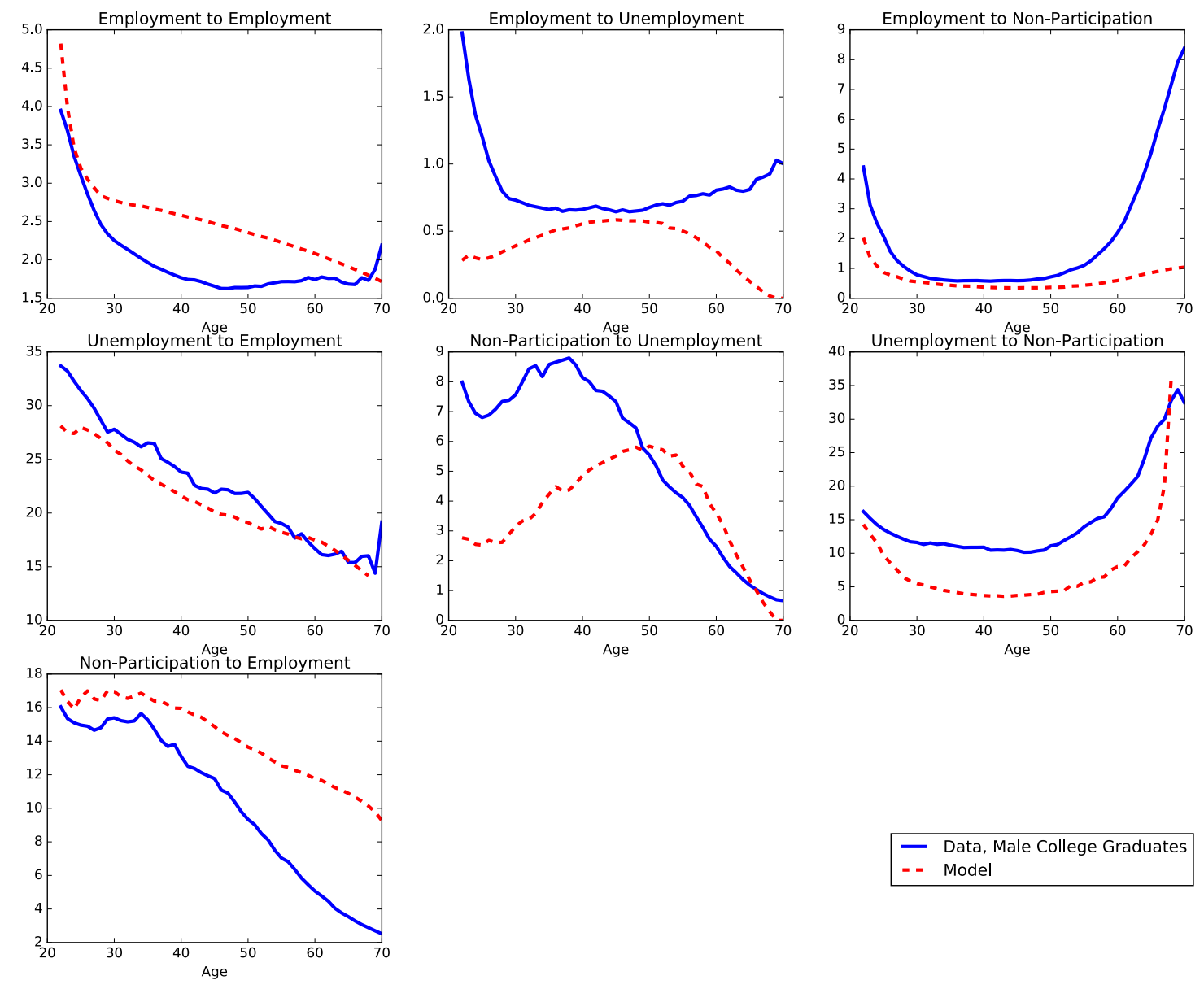

Figure 2.7: Data vs. Model: Monthly labor market flows

and then agents endogenously decide at which point to leave the labor force (i.e., "retire").

Figure 2.7 provides the main results for worker flows 7 We obtain good matches for the flows that involve finding new jobs in a frictional environment (the job-to-job flow, the UE flow, and the NE flow), partly thanks to the age-dependent job offer rates. We obtain a good match with the life-cycle pattern of the UN flow as well.

The model fails the most with the EU flow. While we suspect that the fit can

\footnotetext{
${ }^{7}$ The reported simulation results are from the steady-state version of the model that abstracts from aggregate productivity shocks.
} 
be improved by making $\sigma$ age-dependent, it also represents a structural issue in the model. When a worker is very old, the reward from job search is small, partly because the job offer probability is small and partly because the remaining life period is short. This induces worker to move to the $\mathrm{N}$ state instead of to the $\mathrm{U}$ state.

The EN flow is matched qualitatively, but we do not generate a sufficient amount of "retirement flows" to $\mathrm{N}$ for older workers. This is partly due to the fact that our model does not have old-age transfers such as social security. Various retirement plans also encourage saving in preparation for the old age, inducing workers to accumulate large savings for retirement, and that incentive is not built into the model, either. This is another area in which additional institutional details are necessary in order for the model to match the data. The NU flow matches well with the old age, but young workers do not engage in search activity in the model as much as in the data.

Overall, while the model cannot match all worker flows perfectly, we view the obtained fit as reasonably good, especially given the parsimonious structure of the model. In the next section, we analyze the business-cycle implications utilizing this framework.

In terms of aggregate labor market stocks, the model generates 89 percent labor force participation compared to 83 percent of labor force participation in the data. This is mainly because the model generates higher than the data flow rates from non-participation to employment and it cannot generate the steep increase in the employment to non-participation flow rate as workers get close to 70 . The model generates a 1.8 percent unemployment rate, compared to a 3 percent unemployment rate of male college graduates during 1994-2013. 


\subsubsection{Business Cycle Implications of the Model}

Given that the model performs reasonably well in terms of the steady state patterns of worker flows, we proceed to evaluate the model performance in the business cycle context. Here, we conduct a steady-state comparison of booms and recessions. It has been argued, for example in Shimer (2005), that the U.S. labor market is sufficiently fluid so that the steady-state comparison approximates the aggregate fluctuations in the labor market very well. While it is not obvious whether this assertion translates into our context, this seems to be a reasonable starting point.

Similarly to Krusell et al. (2016), we consider two aggregate states: a good state and a bad state. These states differ with respect to labor market frictions, which can be considered as a stand-in for labor demand fluctuations. The good state is defined as higher job offer probabilities and lower exogenous job separation rate, and the bad state is defined as lower job offer probabilities and higher exogenous job separation rate. Specifically, $\lambda_{i, j}=\lambda_{i}+m_{i} j+\epsilon_{\lambda}$, where $i \in\{e, u, n\}, \lambda_{i}$ is the intercept of the linear job offer function over different ages, and $m_{i}$ is the slope of the function, and $\epsilon_{\lambda}$ is the shock to job offer probabilities. $\epsilon_{\lambda}$ is constant across labor market states and parameterized to be .065 , which corresponds to a 23 percent shock to the job offer probability of an unemployed worker at age 42 . The 23 percent shock value is taken from Krusell et al. (2016). In the good state we increase job offer probabilities by .065 from the calibrated value and in the bad state we decrease job offer probabilities by .065. Similarly, $\sigma=\tilde{\sigma}+\sigma_{\epsilon}$, where $\tilde{\sigma}$ is the calibrated value, and $\sigma_{\epsilon}$ is the shock to the exogenous job separation rate. We parameterize the shock to job separation to be equal to -.001, which corresponds to 13 percent shock to the job separation rate. In the good state, the job separation rate decreases by .001 and the separation rate 

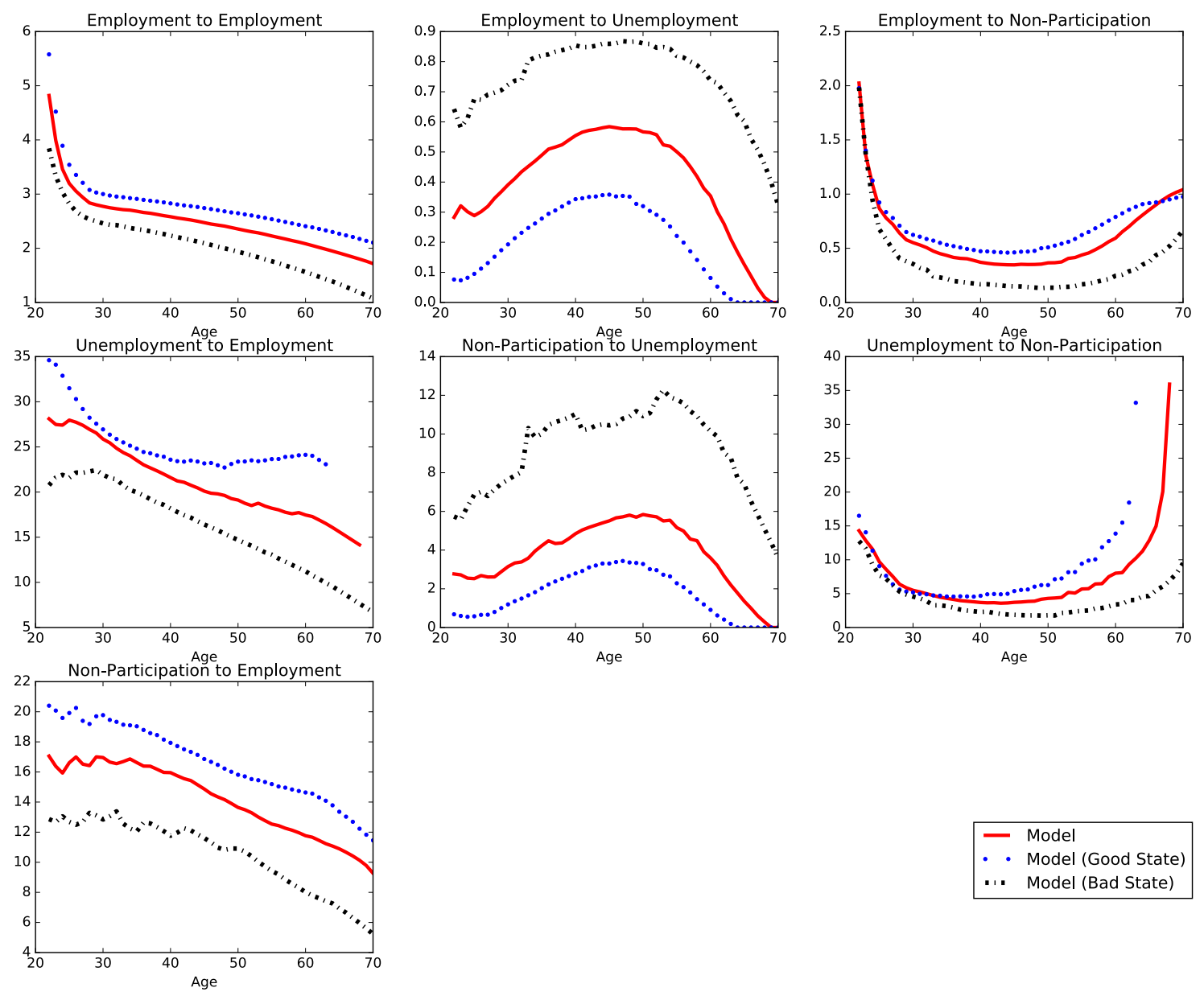

Figure 2.8: Comparison of Good and Bad Steady States

increases by .001 in the bad state.

Figure 2.8 depicts the results of our exercise described above. Recall that Figure 2.4 and the right panel of Figure 2.5 show the flow rates for the recession and boom years in the data, specifically years 2005-2007 for the boom state and years 2008-2010 for the recession state.

Comparing the model outcome to the data, we observe some successes and failures of the model. First of all, the model qualitatively succeeds in matching the overall 
cyclicality of each flow. Job-to-job flow, UE, UN, and NE flows are procyclical while EU and NU flows are countercyclical. It also succeeds in replicating the procyclical EN flow, and the fact that its cyclicality is smaller than the other flows, although the difference is not as stark as in the data.

One notable failure of the model is that, compared to the data, the flows that involve $\mathrm{N}$ (that is, the flows related to the labor supply margin) respond very strongly to the changes in frictions. In particular, the NU and NE flows are almost acyclical for old workers in the data, while the cyclicality is very strong in the model. This may be a result from the fact that the "shock" , $\epsilon_{\lambda}$, is additive, rather than multiplicative. A part of the strong reaction is also coming from the fact that we analyze the steadystate comparison. Krusell et al. (2016) argue that some of the gross flows are affected by slow-moving distributional changes in the long run; therefore, focusing only on long-run comparisons may excessively emphasize the differences between booms and recessions. These points require further investigations in future.

In terms of the aggregate labor market stocks, the model generates 89 percent labor force participation and a .7 percent unemployment rate during the good state and 87 percent labor force participation and a 4.5 percent unemployment rate during the bad state. Therefore, the unemployment rate is more affected by business conditions than the labor force participation, which is qualitatively in line with the data. 


\subsection{Conclusion}

This paper provides an empirical and theoretical analysis of worker flows over the life cycle. We document stark and systematic differences in labor market flows by age for the analyzed group of college graduates.

We then build a parsimonious partial-equilibrium model with heterogeneous workers and labor-market frictions. The steady-state of the model matches the patterns of gross flows relatively well, although there are several flows that miss the properties of particular age groups. The business cycle patterns of the data can be well replicated by the model's steady-state comparisons with different levels of frictions. Quantitatively, the model exhibits too strong reactions of the labor supply margin to the changes in the labor market frictions.

Overall, our model provides a reasonable framework in accounting for the aggregate patterns of gross worker flows over the life cycle and the business cycle. Given that this is the first attempt in the literature to account for the life-cycle patterns of the gross flows that involve the non-participation state, we believe that our framework provides a useful benchmark.

Future research topics include: (i) filling in the institutional details, such as retirement income and school-to-work transitions, to improve the fit of the model to the data; (ii) adjusting the model so that a better quantitative fit to the data is achieved; and (iii) analyzing the life-cycle implications of business cycles on the in-

dividual worker's labor market experiences using our framework. By extending the model to general equilibrium, we will also be able to utilize the model to assess various labor-market policies. 


\section{Bibliography}

Aghion, P and P Howitt (1992), 'A model of growth through creative destruction', Econometrica 60(2).

Akcigit, Ufuk, Douglas Hanley and Stefanie Stantcheva (2016), Optimal taxation and r\&d policies, Technical report, National Bureau of Economic Research.

Atkeson, Andrew and Ariel Burstein (2015), 'Aggregate implications of innovation policy'.

Bloom, Nick, Rachel Griffith and John Van Reenen (2002), 'Do r\&d tax credits work? evidence from a panel of countries 1979-1997', Journal of Public Economics 85(1), 1-31.

CBO, US (2005), R\&d and productivity growth: A background paper, in 'Washington, DC: The Congress of the United States (Congressional Budget Office)(http://www. cbo. gov/ftpdocs/64xx/doc6482/06-17-RD. pdf [6 December 2007])'.

Chéron, Arnaud, Jean-Olivier Hairault and François Langot (2013), 'Life-cycle equilibrium unemployment', Journal of Labor Economics 31(4), 843 - 882. 
Choi, Sekyu, Alexandre Janiak and Benjamín Villena-Roldán (2015), 'Unemployment, participation and worker flows over the life-cycle', The Economic Journal 125(589), 1705-1733.

Cummins, Jason G and Giovanni L Violante (2002), 'Investment-specific technical change in the united states (1947-2000): Measurement and macroeconomic consequences', Review of Economic dynamics 5(2), 243-284.

DiCecio, Riccardo (2009), 'Sticky wages and sectoral labor comovement', Journal of Economic Dynamics and Control 33(3), 538-553.

Elsby, Michael W. L., Bart Hobijn and Ayşegül Şahin (2010), 'The labor market in the great recession', Brookings Papers on Economic Activity 41(1 (Spring), 1-69.

Elsby, Michael W. L., Ryan Michaels and Gary Solon (2009), 'The ins and outs of cyclical unemployment', American Economic Journal: Macroeconomics 1(1), 84110.

Elsby, Michael W.L., Bart Hobijn and Ayşegül Şahin (2013), On the importance of the participation margin for market fluctuations, Working Paper Series 2013-05, Federal Reserve Bank of San Francisco.

Esteban-Pretel, Julen and Junichi Fujimoto (2014), 'Life-cycle labor search with stochastic match quality', International Economic Review 55(2), 575-599.

Foster, Lucia, John C Haltiwanger and Cornell John Krizan (2001), Aggregate productivity growth. lessons from microeconomic evidence, in 'New developments in productivity analysis', University of Chicago Press, pp. 303-372. 
Gomme, Paul, Richard Rogerson, Peter Rupert and Randall Wright (2005), The business cycle and the life cycle, in 'NBER Macroeconomics Annual 2004, Volume 19', NBER Chapters, National Bureau of Economic Research, pp. 415-592.

Gordon, Robert J (1990), 'The measurement of durable goods prices', NBER Books .

Grossman, Gene M and Elhanan Helpman (1991), 'Quality ladders in the theory of growth', The Review of Economic Studies 58(1), 43-61.

Grossmann, Volker, Thomas Steger and Timo Trimborn (2013), 'Dynamically optimal r\&d subsidization', Journal of Economic Dynamics and Control 37(3), 516-534.

Hall, Bronwyn H, Jacques Mairesse and Pierre Mohnen (2010), 'Measuring the returns to r\&d', Handbook of the Economics of Innovation 2, 1033-1082.

Huffman, Gregory W and Mark A Wynne (1999), 'The role of intratemporal adjustment costs in a multisector economy', Journal of Monetary Economics 43(2), 317350.

Jones, Charles I and John C Williams (2000), 'Too much of a good thing? the economics of investment in r\&d', Journal of Economic Growth 5(1), 65-85.

Judd, Kenneth L (1998), Numerical methods in economics, MIT press.

Jung, Philip and Moritz Kuhn (2014), Earnings losses and labor mobility over the lifecycle, Technical report, mimeo.

Kahn, Lisa B. (2010), 'The long-term labor market consequences of graduating from college in a bad economy', Labour Economics 17(2), 303-316. 
Klette, Tor Jakob and Samuel Kortum (2004), 'Innovating firms and aggregate innovation', Journal of political economy 112(5), 986-1018.

Krusell, Per (1998), 'Investment-specific r\&d and the decline in the relative price of capital', Journal of Economic Growth 3(2), 131-141.

Krusell, Per, Toshihiko Mukoyama, Richard Rogerson and Ayşegül Şahin (2016), Gross worker flows over the business cycle, Technical report, mimeo.

Kydland, Finn E. (1984), 'Labor-force heterogeneity and the business cycle', Carnegie-Rochester Conference Series on Public Policy 21(1), 173-208.

Lentz, Rasmus and Dale T Mortensen (2008), 'An empirical model of growth through product innovation', Econometrica 76(6), 1317-1373.

Lentz, Rasmus and Dale T Mortensen (2015), 'Optimal growth through product innovation', Review of Economic Dynamics .

Menzio, Guido, Irina A. Telyukova and Ludo Visschers (2012), Directed search over the life cycle, Working Paper 17746, National Bureau of Economic Research.

Mortensen, Dale T. and Christopher A. Pissarides (1994), 'Job creation and job destruction in the theory of unemployment', Review of Economic Studies 61(3), 397415.

Mukoyama, Toshihiko (2014), 'The cyclicality of job-to-job transitions and its implications for aggregate productivity', Journal of Economic Dynamics and Control $39(\mathrm{C}), 1-17$. 
OECD (2015), 'Oecd science, technology and industry scoreboard 2015'.

URL:/content/book/stis coreboard - 2015 - en; jsessionid $=7$ cdk5kqkid932.x oecd-live -02

Ríos-Rull, José-Víctor (1996), 'Life-cycle economies and aggregate fluctuations', Review of Economic Studies 63(3), 465-89.

Sakellaris, Plutarchos and Daniel J Wilson (2004), 'Quantifying embodied technological change', Review of Economic Dynamics 7(1), 1-26.

Schmitt, John (2003), Creating a consistent hourly wage series from the current population survey's outgoing rotation group, 1979-2002, Technical report, Center for Economic and Policy Research.

Segerstrom, Paul S (2007), 'Intel economics', International Economic Review 48(1), 247-280.

Shimer, Robert (2005), 'The cyclical behavior of equilibrium unemployment and vacancies', American Economic Review 95(1), 25-49.

Shimer, Robert (2012), 'Reassessing the ins and outs of unemployment', Review of Economic Dynamics 15(2), 127-148. 